\title{
Effect of starting microstructure on helium plasma-materials interaction in tungsten
}

Kun Wang, Mark E. Bannister, Fred W. Meyer, and Chad M. Parish*

\begin{abstract}
In a magnetic fusion energy (MFE) device, the plasma-facing materials (PFMs) will be subjected to tremendous fluxes of ions, heat, and neutrons. The response of PFMs to the fusion environment is still not well defined. Tungsten metal is the present candidate of choice for PFM applications such as the divertor in ITER. However, tungsten's microstructure will evolve in service, possibly to include recrystallization. How tungsten's response to plasma exposure evolves with changes in microstructure is presently unknown. In this work, we have exposed hot-worked and recrystallized tungsten to an $80 \mathrm{eV}$ helium ion beam at a temperature of $900^{\circ} \mathrm{C}$ to fluences of $2 \times 10^{23}$ or $20 \times 10^{23} \mathrm{He} / \mathrm{m}^{2}$. This resulted in a faceted surface structure at the lower fluence or short but well-developed nanofuzz structure at the higher fluence. There was little difference in the hotrolled or recrystallized material's near-surface $(\leq 50 \mathrm{~nm})$ bubbles at either fluence. At higher fluence and deeper depth, the bubble populations of the hot-rolled and recrystallized were different, the recrystallized being larger and deeper. This may explain previous high-fluence results showing pronounced differences in recrystallized material. The deeper penetration in recrystallized material also implies that grain boundaries are traps, rather than high-diffusivity paths.
\end{abstract}

(C) 2016. This manuscript version is made available under the Elsevier user license http://www.elsevier.com/open-access/userlicense/1.0/ 


\section{Introduction}

Plasma-facing materials (PFMs) and components (PFCs) in a magnetic fusion energy (MFE) device, such as a tokamak, will be subjected to high fluxes of heat, plasma ions (He and D/T), and neutrons. Because of its high melting point and low sputter yield, tungsten is the primary candidate for MFE applications such as divertors in ITER. Under transient thermal loads, such as might be experienced when a plasma disruption strikes the PFC, the temperature at the surface of the tungsten might undergo a large excursion and result in recrystallization of the material. Macroscopically, recrystallized tungsten has poor mechanical properties in comparison to tungsten with a hot worked or fine-grained structure.

A less explored topic is how changes in the underlying microstructure (such as deformed vs. recrystallized) will affect the interaction of the plasma ions (particularly He) with the underlying material). Studies on deuterium found highly recrystallized material, with very low intrinsic defect density, retained much less deuterium than hot-worked, highly defective material [1]. Phenomenologically, linear plasma devices found comparatively worse helium plasma response in recrystallized material at high plasma fluences [2]. Microscopically, with greatly reduced grain boundary area and dislocation density, recrystallized tungsten presumably undergoes different helium disposition and bubble growth behavior, but this is not well characterized.

Previous work has explored the high-fluence microstructural changes [2-4], and found significant changes in the overall performance of different grades of tungsten after long exposures to He plasmas. Although the differences between most of the tungsten grades were minor, the recrystallized material showed significant growth of nanofuzz deep within the specimen, which is surprising and difficult to explain [2].

Grain boundaries and dislocations have been shown, both by experiment and by calculations, to increase helium trapping and form excess densities of bubbles at the grain 
boundaries or dislocation lines. However, most of the dislocation work on low-energy (subdisplacement-threshold) helium has used theoretical simulations, rather than experiment, and have examined punched dislocation loops from growing bubbles, rather than line dislocations $[5,6]$. However, experiments have indicated that line dislocations will collect helium preferentially $[7,8]$, but comparisons of dislocation effects under low-energy helium across different tungsten microstructures are lacking. Grain boundaries also sequester plasma-introduced helium differently than the matrix. Results from theory approaches (molecular statics and molecular dynamics [MD]) indicated that the $\{112\} 70.5^{\circ} \Sigma 3$ coincident site lattice (CSL) special grain boundary in tungsten would attract significantly more helium, and therefore form larger, denser, and deeper bubbles than the surrounding matrix [9].

A number of computational (primarily MD or related methods) studies have examined the influence of bubble growth on nanotendril fuzz formation. Bubble formation and bursting, especially leading to changes in the local concavity and convexity, appear to drive growth of nanotendrils or surface flaking $[10,11]$. Collection of helium platelets onto $\{101\}$ planes was used to explain scanned-probe microscopy results on faceting tungsten surfaces [12]. Bubbles can also make local nucleation of new satellite bubbles easier [13], and the nucleation of new bubbles within tendrils appears to drive further growth [14]. New grains also appear to nucleate randomly along the length of the growing tendrils [15]. He fluence will also change the disposition of the helium, absent any differences in microstructure. Theory results have indicated that changes in fluence affect the growth of the helium bubbles, where higher flux caused the bubbles to grow with a bias toward the surface, and concomitantly more surface damage [16]. Changes in the propensity for trap mutation as a function of depth (distance from the free surface, and its image forces) were also seen to make trap mutation and loop punching easier in a shallow bubble $[17,18]$.

Although the above summary shows that many pieces of the puzzle of tungsten surface changes under He exposure are known, there are also many unknowns remaining. Particularly, 
much of the previous work has used computational rather than experimental methods, and MD or other theory approaches have trouble reaching the long exposure times at low fluxes needed to match in-tokamak service. Experimental studies (e.g., Refs. $[3,7,8,19,20]$, amongst many others) have well-explored individual aspects of surface morphology changes.

Here, we explore the influence of the starting structure of high-purity tungsten specifically, in a hot-rolled state containing many grain boundaries and dislocations vs. a recrystallized state with very few of these intrinsic defects - on the evolution of the surface morphology and the near-surface microstructure.

We hypothesize that He interaction with pristine or near-pristine matrix, as would be produced in a recrystallized region away from grain boundaries, will show a different bubble size population and bubble distribution than in a highly deformed matrix. Specifically, we hypothesize that in hot-worked material, with more grain boundaries and dislocations, helium bubbles in the matrix are likely to be smaller, owing to easier and denser nucleation at heterogeneous sites. We also hypothesize that in recrystallized material, helium bubbles introduced by helium impingement will be larger and less dense, due to a greater necessity for homogeneous nucleation (such as the trap mutation [21]). Therefore, we exposed hot-worked and recrystallized tungsten to $80 \mathrm{eV} \mathrm{He}$ ions at $900^{\circ} \mathrm{C}$ in order to measure the helium bubble and nanofuzz features to test this hypothesis. We restricted the experiment to moderate fluences $\left(\sim 10^{23}-10^{24} \mathrm{He} / \mathrm{m}^{2}\right)$ in order to avoid the formation of later, high-density defects that would preclude electron microscopic characterization of individual defects.

\section{Experimental procedure}

Samples were high-purity (nominally 99.99\%) tungsten from ESPI metals, USA. The sample was received in the form of hot-rolled plate, $\sim 3 \mathrm{~mm}$ in thickness. Sample coupons were cut to a size 
of $10 \times 15 \times 1 \mathrm{~mm}$ and mechanically polished with $\mathrm{SiC}$ polishing pads, diamond suspension, and a colloidal silica mixture. Some coupons were heat treated under vacuum to $1600^{\circ} \mathrm{C}$ for 2 hours to recrystallize the structure. We will call the hot-rolled samples HR, and the recrystallized, RX.

Helium exposures were performed on the Multicharged Ion Research Facility (MIRF) at ORNL, which uses a deceleration module $[22,23]$ to produce a high-flux $80 \mathrm{eV}$ helium ion beam. In these experiments, peak fluxes were $\sim 1-2 \times 10^{20} \mathrm{He} / \mathrm{m}^{2} \mathrm{sec}$. Exposures were at $900^{\circ} \mathrm{C}$ to nominal fluences of $2 \times 10^{23} \mathrm{He} / \mathrm{m}^{2}$ or $20 \times 10^{23} \mathrm{He} / \mathrm{m}^{2}$, yielding an overall matrix of four conditions: HR $2 \times 10^{23}$, HR $20 \times 10^{23}, \mathrm{RX} 2 \times 10^{23}$, and $\mathrm{RX} 20 \times 10^{23}$. The fluence was delivered over a spot $\sim 2 \times 3 \mathrm{~mm}$ in size and lenticular in shape; SEM, FIB, and TEM were all performed near the geometric center of the beam spot ( $\sim 1 \mathrm{~mm}$ diameter region), where the peak flux occurred. The $\mathrm{RX} 20 \times 10^{23}$ sample actually received an estimated peak fluence of approximately $18 \times 10^{23} \mathrm{He} / \mathrm{m}^{2}(\sim 10 \%$ less $)$, but will be called "RX $20 \times 10^{23 "}$ for consistency. Similarly, the RX $2 \times 10^{23}$ received an estimated fluence of $2.3 \times 10^{23} \mathrm{He} / \mathrm{m}^{2}(\sim 15 \%$ more $)$, but will be called "RX $2 \times 10^{23 "}$ for consistency. Best estimates of fluence for the HR samples are, indeed, 2 and $20 \times 10^{23} \mathrm{He} / \mathrm{m}^{2}$.

Microstructural investigations were performed using a JEOL JSM 6500F field-emission scanning electron microscope (SEM) equipped with electron backscatter diffraction (EBSD). Focused ion beam (FIB) was used to perform sample preparation for scanning/transmission electron microscopy (S/TEM). The FIB used was an FEI Quanta 3D DualBeam ${ }^{\text {TM }}$ FIB-SEM. Additionally, high-resolution SEM and electron-channeling contrast imaging (ECCI) [24] were performed in an FEI Versa 3D DualBeam ${ }^{\text {TM }}$ FIB-SEM equipped with a high-resolution field-emission SEM column, using an annular solid-state backscatter electron detector. ECCI was performed at 30 $\mathrm{keV}$ at very short ( $\sim 4-5 \mathrm{~mm})$ working distance, imaging using the outermost sector of the foursector annular detector. S/TEM was performed using a JEOL JEM2100F S/TEM or an FEI Talos F200X S/TEM. TEM samples from helium-exposed regions were prepared using FIB methods. TEM 
samples from the unirradiated specimens (Figure 2) were prepared by electropolishing $3 \mathrm{~mm}$ disks in an $\mathrm{NaOH}$ solution. Both S/TEMs operated at $200 \mathrm{keV}$. The JEOL JSM 6500F is located in the Materials Characterization Facility (MCF) at ORNL, and the other instruments at the Low Activation Materials Development and Analysis (LAMDA) facility $[25,26]$ at ORNL.

\section{Results}

\section{$\underline{3.1 \text { Surface observations }}$}

The pre-exposure microstructures were those expected for HR and RX microstructures. EBSD maps of the gross microstructures, Figure 1, show the HR and RX grain structures. The HR shows a fine subgrain structure and the RX shows large, nearly strain-free, grains; Figures 1a-b. Grain sizes are HR: $2.2 \pm 2.0 \mu \mathrm{m}$ and RX: $16.1 \pm 10.3 \mu \mathrm{m}$. These values are mean \pm standard deviation of the equivalent diameters, and with a $5^{\circ}$ misorientation needed to define a grain boundary (grain tolerance angle). These calculations were performed using EDAX OIM-Analysis software, v7. The distributions are positively skewed, with most grains below the mean and a small number of outliers above the mean.

Inverse pole figure calculations of the texture in the Z-direction indicate strong $<001>$ preferred orientation in both samples; the HR sample shows some $<101>$ and $<111>$ grains, and the RX shows nearly equal preponderance of $<001>$ and $<111>$ with little $<101>$. Figure 1 c-d show that the RX shows a peak texture of $\sim 5 \times$ random vs. $\sim 3 \times$ random in the HR, indicating less texture in the HR. (Absolutely no EBSD data "cleaning" [27] was performed.)

The HR samples showed a very high density of dislocations, and the recrystallized, a very low density. This is visible qualitatively in the plan-view ECCI images and in TEM images, Figure 2. Many dislocations and grain boundaries are visible in the HR, and large grains with few internal defects are seen in the RX. 
After He exposure there are visible differences in the HR and RX specimen surfaces. At $2 \times 10^{23} \mathrm{He} / \mathrm{m}^{2}$, the RX material shows cusps or dips at the grain boundaries (Figures $3-4$, top rows) which are not visible in the HR samples with the $2 \times 10^{23} \mathrm{He} / \mathrm{m}^{2}$ fluence. This is because the samples were polished prior to recrystallization, and grain-boundary grooving occurred during recrystallization prior to helium exposure. In the $20 \times 10^{23} \mathrm{He} / \mathrm{m}^{2}$ fluence samples, there are grainto-grain differences in the apparent depth of the tendril mat (Figure 3, bottom row), but the general structure of a dense nanotendril mat is not markedly different between the two conditions, HR and RX. At higher magnification (Figure 4) these differences are more visible, but relatively minor.

There is a small difference in the quantitative tendril widths between the HR and RX samples at $20 \times 10^{23} \mathrm{He} / \mathrm{m}^{2}$. A number of high resolution SEM images (FEI Versa 3D, operated with a short working distance, $\sim 4-5 \mathrm{~mm}$, and $5 \mathrm{keV}$ beam energy, in-column electron detector) were acquired from discreet grains across the breadth of the beam-exposed spots, sampling regions up to about a millimeter apart, taking care to stay within the peak flux of the beam. Analysis (using ImageJ software ${ }^{1}$ ) of the tendril widths, both grain by grain and collectively for the HR and RX samples, is given in Table I and the bottom row of Figure 4. Specifically, the HR samples showed $27.6 \pm 9.1 \mathrm{~nm}$ (mean \pm 1 standard deviation) tendril width, and the RX samples $32.8 \pm 9.2 \mathrm{~nm}$. Although the histograms are overlapped (Figure 4), and the means differ by only about one-half of a standard deviation, the two samples do appear to provide statistically distinct distributions. A $10^{4}$ bootstrap (resampling-with-replacement, MATLAB 'bootstrp') analyses of the means of each dataset provide well-separated histograms; a two-sample Kolmogorov-Smirnov test (MATLAB 'kstest2') provided p 10-16, allowing rejection of the hypothesis that both datasets are drawn from the same distribution. Possible origins of this observation of differing tendril widths will be discussed in Section 4.

\footnotetext{
${ }^{1}$ United States National Institutes of Health: https://imagej.nih.gov/ij/
} 


\section{$\underline{3.2 \text { Cross-sectional observations }}$}

The $2 \times 10^{23} \mathrm{He} / \mathrm{m}^{2}$ samples show subsurface bubbles and some surface roughness, and the $20 \times 10^{23} \mathrm{He} / \mathrm{m}^{2}$ samples showed short but well-developed nanotendril fuzz. Figure 5 shows the cross sectional TEM micrographs of HR and RX W exposed with $2 \times 10^{23}$ and $20 \times 10^{23} \mathrm{He} / \mathrm{m}^{2}$ fluence at low magnification. Many bubbles/cavities are seen in the $2 \times 10^{23} \mathrm{He} / \mathrm{m}^{2}$ samples, and surface faceting is beginning to develop, as indicated in the SEM observations above. In the $20 \times 10^{23} \mathrm{He} / \mathrm{m}^{2}$ samples, many large He bubbles or cavities, as well as pinholes, are observed inside tendrils and in the layer just under the bottom of the tendrils.

He bubbles penetrate deeply beneath the surface as indicated by the white arrow in Figure 6a. For quantitative analysis, the helium bubbles were binned into depth ranges of 0-50 nm, 50-100 $\mathrm{nm}$, and $>100 \mathrm{~nm}$ below the surface for all the samples. The average diameter of He bubbles is given in Table II and Figure 7. As shown in Figure 6 (a)-(d), in the range of 0-50 nm, high densities of small helium bubbles were observed together with larger cavities, but in the range of 50-100 nm, most of bubbles are fairly small, except for a very few larger cavities. In the range of $>100 \mathrm{~nm}$, all the bubbles are much smaller and exhibit a narrow size distribution. 


\section{Discussion}

Several of the observations listed in Sections 3.1 and 3.2 bear further discussion: (1) Changes in microstructure with annealing. (2) Variations in tendril width for the HR vs. RX specimens. (3) Lack of changes in tendril width from grain-to-grain in the same specimens. (4) Differences in helium bubble and cavity sizes among the four conditions. (5) Differences in bubble maximum depth of penetration among the four conditions.

(1)The grain size differences and texture differences (Figure 1) are broadly expected from recrystallization processing of rolled BCC sheet [28], although a stronger $<111>$ component is seen here than in some previous tungsten recrystallization results [29]. The grain boundary misorientations differ widely in the HR vs. RX state; in the HR samples many low-angle subgrain boundaries are observed, and in the RX samples fewer but higher-angle grain boundaries are 
present. The differences in dislocation densities observed in ECCI, shown in Figure 2, are fully expected from the recrystallization.

(2) Variations in tendril width, $27.6 \pm 9.1 \mathrm{~nm}$ for $\mathrm{HR}$ and $32.8 \pm 9.2 \mathrm{~nm}$ for $\mathrm{RX}$, are more difficult to explain. The variations are probably real rather than due to sampling error, as mentioned above in Section 3.1. The differences are, however, small (about $1 / 2$ of the standard deviations). The question is if the differences can be attributed to the starting microstructure, HR vs. RX, or to the inevitable variations in growth conditions from sample-to-sample by the ion beam exposures. Uncertainty in the fluence for the nominally $20 \times 10^{23} \mathrm{He} / \mathrm{m}^{2}$ samples was estimated at $\pm 3 \times 10^{23} \mathrm{He} / \mathrm{m}^{2}$, and fluxes at $1.0-1.6 \times 10^{20} \mathrm{He} / \mathrm{m}^{2} \mathrm{sec}$. (Beam current in $\mu \mathrm{A}$ are measured through a $1 \mathrm{~mm}^{2}$ Faraday cup aperture, and then mapped in space to provide a beam flux profile, and converted to fluence through exposure time.) Kajita et al [30] observed that the width of the nanotendrils decreases with increasing helium fluence. The $20 \times 10^{23} \mathrm{He} / \mathrm{m}^{2} \mathrm{RX}$ sample's dosimetry indicated its fluence was slightly $\left(\sim 2 \times 10^{23} \mathrm{He} / \mathrm{m}^{2}\right)$ lower than the HR sample. Based on the Kajita results, a slightly thicker tendril structure is possible in the RX compared to HR, due purely to fluence. However, Kajita et al. reported a very gradual change in tendril diameter with fluence, so the magnitude of difference in tendril diameter $(\sim 15 \%)$ resulting from a $\sim 10 \%$ difference in fluence would be surprising. However, because the results of Kajita et al. were at much higher temperature $\left(\sim 1100^{\circ} \mathrm{C}\right.$ vs. $900^{\circ} \mathrm{C}$ here), and indeed they found a fluence threshold of $\sim 10^{25} \mathrm{He} / \mathrm{m}^{2}$ to form tendrils at all, we suggest caution before comparing the two sets of results. Therefore, it is possible, but not necessarily likely, that the difference in tendril thickness arises from the very small variations in fluence.

Other possible explanations for the different tendril diameters from RX to HR are that reduced residual stress in the specimen arising from the low dislocation-density in the RX could result in changes to the growth morphology, or that dislocations could act as He trapping or bubble 
nucleation sites, resulting in a higher density of tendril nucleation events in the HR and concomitantly smaller tendrils.

(3) The lack of differences in grain-to-grain tendril width (Table I) for either material condition indicates that the grains' crystallographic orientation is not determinative of the fuzz diameter. The lower fluence $2 \times 10^{23} \mathrm{He} / \mathrm{m}^{2}$ samples showed significant differences in the surface morphologies from grain to grain, and these changes have previously been correlated to surface normal orientation of the grains [31,32]. (Our previous hypothesis [32] that certain surface normals such as $<102>$ to $<103>$ may be resistant to tendril formation is clearly only true up to a point. Beyond a certain point, which may be in fact be flux dependent [23], any grain appears to grow a thick mat of fuzz.)

(4) - (5) Related to the differences in the tendril widths, differences in the bubble diameters and depth distributions are also observed. Most easily visible in Table II, the near surface (0-50 nm) bubbles are similar in size for the HR and RX specimens. At $20 \times 10^{23} \mathrm{He} / \mathrm{m}^{2}$ the differences in bubble size are minor, although the $2 \times 10^{23} \mathrm{He} / \mathrm{m}^{2} \mathrm{HR}$ sample shows bubbles $\sim 20 \%$ smaller than the RX sample (but the two are within a standard deviation of each other). Because of the natural polydispersity of bubble-size distributions, it is statistically difficult to determine if the two distributions are in fact statistically distinct in the RX vs. HR at given fluence $\left(2\right.$ or $\left.20 \times 10^{23}\right)$ and depth $(0-50,50-100$, or $100+\mathrm{nm})$.

The Kolmogorov-Smirnov (K-S) test (MATLAB 'kstest2') is a non-parametric test that can help determine if two datasets are distinct, although no statistical test is infallible, and the p-values returned must be carefully interpreted in light of the actual microstructures. Table III provides results for the K-S test determined p-values for the six pairs of intragranular bubbles. The p-value of 0.46 for the shallow $0-50 \mathrm{~nm}$ bubbles in the $2 \times 10^{23}$ samples gives the appearance that the distributions are similar, which is to say, we reject the hypothesis that the HR and RX bubble sizes 
are drawn from different distributions. The other distributions (p-values of 0.03 or less) appear to all be distinct.

However, a few caveats are needed. Relatively few bubbles are counted in the deep regions $(100+n m$ in particular), so statistics are less reliable. The empirical cumulative distributions functions for the twelve datasets are shown in Figure 10, compared as the six sets. For the deeper regions - 50-100 $\mathrm{nm}$ and 100+ $\mathrm{nm}$ - the distributions between the HR and RX do appear very different, more so at $2 \times 10^{23} \mathrm{He} / \mathrm{m}^{2}$ than at $20 \times 10^{23} \mathrm{He} / \mathrm{m}^{2}$. The shallow regions, $0-50 \mathrm{~nm}$, at both fluences gives very little appearance of difference in their CDFs, even though the p-value for $20 \times 10^{23} \mathrm{He} / \mathrm{m}^{2}$ is comparatively small.

Based on comparisons of the histograms in Figure 7, the mean \pm standard deviation values in Table II, the micrographs in Figure 6, and the comparisons in Table III, we conclude that:

- The shallowest regions (0-50 nm) do not appear to show much difference between the HR and RX states, although there may be a slight difference at $20 \times 10^{23} \mathrm{He} / \mathrm{m}^{2}$.

- The deeper regions (50-100 nm, 100+ nm) do show statistically significant differences between the HR and RX states.

- This difference in the deeper regions is larger at $2 \times 10^{23} \mathrm{He} / \mathrm{m}^{2}$ than at $20 \times 10^{23} \mathrm{He} / \mathrm{m}^{2}$.

Generally, low-energy He implantation is expected to form bubble nuclei via the trap mutation mechanism $[9,17,18]$, where several helium atoms agglomerate and force a tungsten atom off its site, forming a Frenkel pair. The vacancy, now loaded with perhaps 4 to 8 helium atoms, will serve as an immobile embryo for a growing bubble, and the interstitial will likely migrate to the surface and can become an adatom to start forming a nanotendril. Is it possible, in addition, that dislocations near the surface help nucleate bubbles? Bubble nucleation was seen in theory approaches for the punched dislocation loops arising from bubble growth [6], and might be expected from pre-existing dislocations. However, because we do not see a statistical difference in 
the near-surface region $(0-50 \mathrm{~nm})$, it appears that trap mutation, rather than heterogeneous nucleation on pre-existing defects, is likely dominant. Although the $20 \times 10^{23} \mathrm{He} / \mathrm{m}^{2}, 0-50 \mathrm{~nm}$ comparison shows a small (0.024) p-value, the similarities of the CDFs (Figure 10) and histograms (Figure 7) lead us to conclude that the actual differences are minor or negligible. It appears that over the range of fluence studied here, the near-surface regions are behaving similarly and the preexisting defects make little difference.

In terms of defects, we do see apparent associations of the helium bubbles with the dislocations, particularly in the HR $2 \times 10^{23} \mathrm{He} / \mathrm{m}^{2}$ sample. (This requires the standard caution that TEM methods provide 2D images of 3D structures, making unambiguous association of two features in a TEM image problematic.) Simultaneous imaging of bubbles and dislocations is difficult, especially in a sample with relaxation or bending where Bragg conditions vary over small local areas, as is the case in these helium-exposed tungsten specimens. However, combining STEM bright-field dislocation contrast [33] with STEM Fresnel imaging makes simultaneous imaging of the dislocations and bubbles/cavities possible, Figure 11. A high density of bubbles is present, along with many dislocation lines. Not all of the bubbles are associated with (visible) dislocation lines, and the near-surface $(<50 \mathrm{~nm})$ region is so damaged that it is difficult to tell which bubbles might be near a dislocation. However, slightly deeper into the specimen, many dislocations appear to be bubble-decorated (arrows). This implies that at least some heterogeneous nucleation is possible, but a definitive understanding of the impact of the dislocation lines on bubble nucleation and tendril width will require further work, both experimental and computational.

In contrast to the $0-50 \mathrm{~nm}$ region, the deeper regions do show differences in the bubble distributions (Figure 10). Specifically, the RX material shows much larger bubbles/cavities than the HR material. This is more pronounced at $2 \times 10^{23} \mathrm{He} / \mathrm{m}^{2}$ than at $20 \times 10^{23} \mathrm{He} / \mathrm{m}^{2}$. Overall, this likely means that the helium can penetrate more readily into the RX structure. At the higher fluence, the 
difference is less pronounced, although bubbles at deep grain boundaries are more apparent in the RX material.

We recall our original hypothesis stated in Section 1, that in HR, with more grain boundaries and dislocations, helium bubbles in the matrix would be smaller, owing to easier and denser nucleation at heterogeneous sites compared to RX. This hypothesis is clearly incorrect in the nearsurface region, but appears to be at least partially true in the sub-surface region.

In the deeper regions, $50-100 \mathrm{~nm}$ and $>100 \mathrm{~nm}$, bubbles in the RX samples are larger than in the HR samples, for both the 2 and $20 \times 10^{23} \mathrm{He} / \mathrm{m}^{2}$ fluences. The RX samples also show deeper grain-boundary bubble penetration, larger grain boundary bubbles, and deeper intragranular bubble penetration, than the HR samples. This is most likely due to stronger trapping of He in the higher-defect-density HR samples, meaning that less He is available to diffuse into the substrate compared to the RX samples.

In previous work comparing the nanotendril growth of various $\mathrm{W}$ grades, Baldwin et al. [2] found that none of the investigated pure- or doped-W grades resisted formation of nanotendril fuzz. Even single crystal W, with an exceptionally low concentration of pre-existing defects, readily grew fuzz comparable to the other W grades. Therefore, Baldwin et al. [2] speculated that nanostructuring is related to a He-trapping mechanism that is self-driven and He clustering followed by He bubbles and nanostructuring should depend on the He concentration in the lattice or the incident energetic He flux to the surface. The most likely mechanism to explain the formation of nanostructure surface morphology is the trap mutation, which produces immobilized heliumvacancy complexes together with a number of surface adatoms. Dislocations and grain boundaries are known to serve as effective sinks to trap the high-mobility helium atoms. Compared with RX W, extended and dense dislocations and grain boundaries dominate the HR W in our present work. The present results (to much lower fluences than in Ref. [2]) are broadly consistent, in that helium 
bubbles - a necessary prerequisite to tendril growth - are pushing more deeply into the RX microstructure than the HR microstructure. Similarly, the RX specimens' grain boundaries (Figure 9) show very deep bubble penetration.

We propose that grain boundaries act as strong traps, rather than fast diffusion paths, to explain these results. In hypothesis (1), where grain boundaries act as high diffusivity paths, the helium would percolate more readily into the HR structure and allow deeper penetration into the substrate. This would provide more helium, and larger cavities, deeper into the structure of the HR than the RX, although a few deep cavities near or on grain boundaries in RX would be expected. This Hypothesis 1 is illustrated schematically in the left column of Figure 12.

Alternatively, in Hypothesis 2, where grain boundaries act as strong traps that capture and immobilize helium (Figure 12 right), we can picture helium diffusing through the grain interiors away from the surface and toward the bulk. Grain boundaries and dislocations will then tend to capture the helium and sequester it, reducing the inventory with depth. This reduction vs. depth will be much faster in the HR than the RX due to the increased defect trapping. It seems possible that trap mutation (and associated strong bubble/cavity nucleation) requires a high local helium inventory, and as we push deeper away from the surface, the lower helium inventory leads to a much lower rate of bubble nucleation. Thus, as seen in Figure 9, bubbles in the deep region are most likely to form at a location such as a grain boundary where trapping is stronger.

Thus, the higher density of grain boundaries (and dislocations) in the HR material appears to consume the helium before it can penetrate deeply into the surface. In quantitative terms, the EBSD data (Figure 1) indicates aggregate grain boundary length is the HR sample is $\sim 10^{6} \mathrm{~m} / \mathrm{m}^{2}$ and in the $\mathrm{RX} \sim 10^{5} \mathrm{~m} / \mathrm{m}^{2}$, for grain boundary segments $\geq 2^{\circ}$. (Aggregate grain boundary length in the $\mathrm{RX}$ was calculated after a light data cleanup [27] step to remove the polishing scratches; for HR, raw 
data was used.) We infer that this $\sim 10 \times$ factor increase in grain boundary area is likely to be a major contribution to the differences in sub-surface microstructure.

Overall, there are large similarities between the HR and RX specimens under these exposure conditions, and even when the differences (tendril width, bubble size) are statistically significant, they are for the most part minor. Only in the very deep regions of the specimen, and down the grain boundaries, do the differences become large. The literature results of Baldwin et al. [2], with a similar temperature $\left(\sim 850^{\circ} \mathrm{C}\right)$ but much higher fluence $\left(>10^{26} \mathrm{He} / \mathrm{m}^{2}\right)$, showed significant differences between RX W and a stress-relieved W (similar to the HR in this work). It appears that despite the similarities in surface morphology and bubble sizes at $20 \times 10^{23} \mathrm{He} / \mathrm{m}^{2}$, the underlying processes that result in the very different structures at higher fluence and flux (such as [2] observed) are beginning to manifest in the $20 \times 10^{23} \mathrm{He} / \mathrm{m}^{2}$ specimens seen in this work, specifically the deep bubbles forming in the RX material.

\section{Conclusions}

We exposed two very different microstructures of tungsten - hot rolled (HR) and recrystallized $(\mathrm{RX})$ - to helium ion beams to simulate early states of tokamak plasma exposure, in order to help determine the mechanisms of helium disposition in tungsten plasma-facing components. Two relatively low fluences, 2 and $20 \times 10^{23} \mathrm{He} / \mathrm{m}^{2}$, were chosen in order to ensure that individual defects, such as bubbles and dislocations, were still visible and could be individually sized and counted, obtained using He ion beam fluxes in the range $1-2 \times 10^{20} / \mathrm{m}^{2} \mathrm{~s}$.

At $2 \times 10^{23} \mathrm{He} / \mathrm{m}^{2}$, surface morphologies varied strongly from one grain to the next, but the HR and RX samples showed indistinguishable directly-subsurface $(<50 \mathrm{~nm}$ depth) bubble sizes, but quite different bubble sizes in the deeper ( $>50 \mathrm{~nm}$ ) regions. By $20 \times 10^{23} \mathrm{He} / \mathrm{m}^{2}$, the surface 
morphologies were similar with grain-to-grain differences minimized, but the very near-surface bubble-size distributions were very slightly different; nanotendrils were slightly thicker in RX than HR material. However, penetration of the grain boundaries and intragranular regions by helium bubbles was beginning, and far more pronounced in the RX than the HR material. This is consistent with literature results in accelerated degradation of RX tungsten at high $\left(\sim 10^{26} \mathrm{He} / \mathrm{m}^{2}\right)$ fluence exposures. We hypothesize that due to easy near-surface trap mutation, dislocations and grain boundaries are not very effective in capturing helium in the near-surface region, but deeper in the material the influence of the dislocations and grain boundaries becomes more pronounced.

Despite the superficial similarities in the near-surface region at $20 \times 10^{23} \mathrm{He} / \mathrm{m}^{2}$, the apparent similarity of the RX and HR grades is illusory, in that although the nanotendrils and bubbles are grossly similar, the penetration of the sample by deep helium bubbles is beginning in the RX material, but not the HR material. We infer that this difference will eventually lead to the divergent behavior observed by Baldwin et al. A qualitative hypothesis of increased loss of helium inventory to grain boundary surface area is proposed to explain the shallower penetration in the HR samples.

\section{Acknowledgements}

This work was supported by US Department of Energy, Office of Science, Fusion Energy Sciences, via an Early Career Research Program Award (ERAT923, PI Chad M. Parish). This research was performed, in part, using instrumentation (FEI Talos F200X) provided by the Department of Energy, Office of Nuclear Energy, Fuel Cycle R\&D Program and the Nuclear Science User Facilities. 


\section{References}

[1] A. Manhard, K. Schmid, M. Balden, W. Jacob, Influence of the microstructure on the deuterium retention in tungsten, Journal of Nuclear Materials, 415 (2011) S632-S635.

[2] M.J. Baldwin, R.P. Doerner, Formation of helium induced nanostructure 'fuzz' on various tungsten grades, Journal of Nuclear Materials, 404 (2010) 165-173.

[3] M.J. Baldwin, R.P. Doerner, Helium induced nanoscopic morphology on tungsten under fusion relevant plasma conditions, Nuclear Fusion, 48 (2008) 035001.

[4] M.J. Baldwin, T.C. Lynch, R.P. Doerner, J.H. Yu, Nanostructure formation on tungsten exposed to lowpressure rf helium plasmas: A study of ion energy threshold and early stage growth, Journal of Nuclear Materials, 415 (2011) S104-S107.

[5] S. Krasheninnikov, R. Smirnov, He cluster dynamics in fusion related plasma facing materials, Nuclear Fusion, 55 (2015) 073005.

[6] R. Smirnov, S. Krasheninnikov, J. Guterl, Atomistic modeling of growth and coalescence of helium nanobubbles in tungsten, Journal of Nuclear Materials, 463 (2015) 359-362.

[7] O. El-Atwani, S. Gonderman, S. Suslov, M. Efe, G. De Temmerman, T. Morgan, K. Bystrov, K. Hattar, J. Allain, Early stage damage of ultrafine-grained tungsten materials exposed to low energy helium ion irradiation, Fusion Engineering and Design, 93 (2015) 9-14.

[8] 0. El-Atwani, J.A. Hinks, G. Greaves, S. Gonderman, T. Qiu, M. Efe, J.P. Allain, In-situ TEM observation of the response of ultrafine- and nanocrystalline-grained tungsten to extreme irradiation environments, Scientific Reports, 4 (2014).

[9] L. Hu, K.D. Hammond, B.D. Wirth, D. Maroudas, Interactions of mobile helium clusters with surfaces and grain boundaries of plasma-exposed tungsten, Journal of Applied Physics, 115 (2014) 173512.

[10] L. Pentecoste, P. Brault, A.-L. Thomann, P. Desgardin, T. Lecas, T. Belhabib, M.-F. Barthe, T. Sauvage, Low Energy and low fluence helium implantations in tungsten: Molecular dynamics simulations and experiments, Journal of Nuclear Materials, 470 (2016) 44-54. 
[11] A. Ito, A. Takayama, Y. Oda, T. Tamura, R. Kobayashi, T. Hattori, S. Ogata, N. Ohno, S. Kajita, M. Yajima, Molecular dynamics and Monte Carlo hybrid simulation for fuzzy tungsten nanostructure formation, Nuclear Fusion, 55 (2015) 073013.

[12] Q. Yang, Y.-W. You, L. Liu, H. Fan, W. Ni, D. Liu, C. Liu, G. Benstetter, Y. Wang, Nanostructured fuzz growth on tungsten under low-energy and high-flux He irradiation, Scientific Reports, 5 (2015).

[13] D. Perez, L. Sandoval, B.P. Uberuaga, A.F. Voter, The thermodynamic and kinetic interactions of He interstitial clusters with bubbles in W, Journal of Applied Physics, 119 (2016) 203301.

[14] S. Krasheninnikov, R. Smirnov, He cluster dynamics in W in the presence of cluster induced formation of He traps, Physica Scripta, T167 (2016) 014021.

[15] C.M. Parish, K. Wang, R.P. Doerner, M.J. Baldwin, Grain orientations and grain boundaries in tungsten nonotendril fuzz grown under divertor-like conditions, Scripta Materialia, 127 (2017) 132-135.

[16] L. Sandoval, D. Perez, B.P. Uberuaga, A.F. Voter, Competing Kinetics and He Bubble Morphology in W, Physical review letters, 114 (2015) 105502.

[17] J. Wang, L.-L. Niu, X. Shu, Y. Zhang, Stick-slip behavior identified in helium cluster growth in the subsurface of tungsten: effects of cluster depth, Journal of Physics: Condensed Matter, 27 (2015) 395001. [18] L. Hu, K.D. Hammond, B.D. Wirth, D. Maroudas, Molecular-dynamics analysis of mobile helium cluster reactions near surfaces of plasma-exposed tungsten, Journal of Applied Physics, 118 (2015) 163301. [19] O. El-Atwani, M. Efe, B. Heim, J.P. Allain, Surface damage in ultrafine and multimodal grained tungsten materials induced by low energy helium irradiation, Journal of Nuclear Materials, 434 (2013) 170-177. [20] S. Kajita, W. Sakaguchi, N. Ohno, N. Yoshida, T. Saeki, Formation process of tungsten nanostructure by the exposure to helium plasma under fusion relevant plasma conditions, Nuclear Fusion, 49 (2009).

[21] F. Sefta, K.D. Hammond, N. Juslin, B.D. Wirth, Tungsten surface evolution by helium bubble nucleation, growth and rupture, Nuclear Fusion, 53 (2013) 073015.

[22] H. Hijazi, F.W. Meyer, A large-acceptance beam-deceleration module for retrofitting into ion-source beam lines, Review of Scientific Instruments, 84 (2013) 033305.

[23] F. Meyer, H. Hijazi, M. Bannister, K. Unocic, L. Garrison, C. Parish, Flux threshold measurements of He-ion beam induced nanofuzz formation on hot tungsten surfaces, Physica Scripta, T167 (2016) 014019. 
[24] A. Manhard, S. Kapser, L. Gao, M. Balden, S. Elgeti, T. Schwarz-Selinger, T. Plocinski, J. Grzonka, M. Gloc, Ł. Ciupinski, Microstructure and Defect Analysis in the Vicinity of Blisters in Polycrystalline Tungsten, in: 22nd International Conference on Plasma Surface Interactions in Controlled Fusion Devices (PSI 22), 2016.

[25] C.M. Parish, N.K. Kumar, L.L. Snead, P.D. Edmondson, K.G. Field, C. Silva, A.M. Williams, K. Linton, K.J.

Leonard, LAMDA: Irradiated-Materials Microscopy at Oak Ridge National Laboratory, Microscopy and Microanalysis, 21 (2015) 1003-1004.

[26] C.M. Parish, MT3FT-150R0204122: Report on the acquisition and installation of FEI Talos F200X S/TEM, Oak Ridge National Laboratory (ORNL), Oak Ridge, TN (United States), 2015.

http://www.osti.gov/servlets/purl/1234344/.

[27] L.N. Brewer, J.R. Michael, Risks of "cleaning" electron backscatter diffraction data, Microscopy Today, 18 (2010) 10-15.

[28] F.J. Humphreys, M. Hatherly, Recrystallization and Related Annealing Phenomena, Elsevier Science Ltd., Oxford, 1996.

[29] L.N. Brewer, B.P. Bewlay, EBSD Characterization of Texture in Tungsten-Rhenium Foils, Microscopy and Microanalysis, 8 (2002) 696-697.

[30] S. Kajita, N. Yoshida, R. Yoshihara, N. Ohno, M. Yamagiwa, TEM observation of the growth process of helium nanobubbles on tungsten: Nanostructure formation mechanism, Journal of Nuclear Materials, 418 (2011) 152-158.

[31] O. El-Atwani, G. Sean, E. Mert, T. Gregory De, M. Thomas, B. Kirill, K. Daniel, Q. Tian, J.P. Allain, Ultrafine tungsten as a plasma-facing component in fusion devices: effect of high flux, high fluence low energy helium irradiation, Nuclear Fusion, 54 (2014) 083013.

[32] C.M. Parish, H. Hijazi, H.M. Meyer III, F.W. Meyer, Effect of tungsten crystallographic orientation on Heion-induced surface morphology changes, Acta Materialia, 62 (2014) 173-181.

[33] P.J. Phillips, M.C. Brandes, M.J. Mills, M. De Graef, Diffraction contrast STEM of dislocations: Imaging and simulations, Ultramicroscopy, 111 (2011) 1483-1487. 


\section{Figure captions}

Figure 1: EBSD data for the HR and RX samples. (a-b) Color scale is the inverse pole figure maps showing out-of-the-page (Z) direction crystallographic orientation, and intensity is the EBSD pattern image quality. Color key is in the bottom-right of (a). Note very different scale bars in (a) and (b). (c-d) inverse pole figures showing strong textures out of the surface of the coupons.

Figure 2: Starting microstructures of the HR and RX materials, as examined by ECCI and TEM.

Figure 3: Low-magnification SEM images showing the relative effects of microstructure and fluence. Note the more pronounced grain boundaries in the recrystallized (RX) sample. Flux $\sim 10^{20} \mathrm{He} / \mathrm{m}^{2} \mathrm{sec}$, $E=80 \mathrm{eV}, \mathrm{T}=900^{\circ} \mathrm{C}$.

Figure 4: Higher-magnification SEM images showing the relative effects of microstructure and fluence. Arrow in the top right image denotes suppression of morphology growth at a grain boundary. Histogram (bottom row) is an analysis of multiple grains each of the $20 \times 10^{23} \mathrm{He} / \mathrm{m}^{2}$ samples' tendril diameters.

Figure 5: Low-magnification TEM images showing the effects of microstructure and fluence. The granulated contrast at the top of each image is the FIB protective layer and is a sample preparation artifact.

Figure 6: High-magnification TEM images showing the relative effects of microstructure and fluence. Flux $\sim 10^{20} \mathrm{He} / \mathrm{m}^{2} \mathrm{sec}, \mathrm{E}=80 \mathrm{eV}, \mathrm{T}=900^{\circ} \mathrm{C}$. 
Figure 7: Size distribution of Helium cavities in various depth ranges below surface for all microstructure and fluence conditions.

Figure 8: TEM images of He bubbles distribution along grain boundaries (GBs) under different microstructure and fluence conditions.

Figure 9: TEM images showing He bubbles permeating deeply along GBs below the surface in recrystallized $W$. The insets indicate bubble microstructures in magnified images.

Figure 10: Empirical cumulative distribution functions for the six comparisons. Also marked are the pvalues from Table III.

Figure 11: HR $2 \times 10^{23} \mathrm{He} / \mathrm{m}^{2}$, bright-field scanning transmission electron microscopy image with a very small bright field collection angle. Dislocations are visible by tilting sample off $\boldsymbol{B} \sim<110>$ to a near-two-beam condition $\boldsymbol{g} \sim(\overline{1} 10)$, see inset. FEI F200X Talos S/TEM.

Figure 12: Schematic illustration of two hypothesized grain boundary effects on helium permeation into the hot rolled and recrystallized structures. We propose Hypothesis (2) as more likely. 


\section{Tables}

Table I: Tendril width measurements from high-resolution SEM images of the $20 \times 10^{23} \mathrm{He} / \mathrm{m}^{2}$ samples.

\begin{tabular}{|c|c|c|c|c|}
\hline \multicolumn{2}{|c|}{$20 \times 10^{23} \mathrm{He} / \mathrm{m}^{2}$} & \multicolumn{2}{|c|}{$\begin{array}{c}\text { Mean Std. Dev. } \\
\text { Diameter, nm }\end{array}$} & \multirow{2}{*}{$\begin{array}{l}\text { Count } \\
524\end{array}$} \\
\hline \multirow{8}{*}{ Hot rolled } & Total & 27.6 & 9.1 & \\
\hline & Grain 1 & 24.3 & 6.1 & 55 \\
\hline & Grain 2 & 27.3 & 8.4 & 100 \\
\hline & Grain 3 & 26.9 & 8.7 & 55 \\
\hline & Grain 4 & 26.6 & 8.0 & 71 \\
\hline & Grain 5 & 26.1 & 8.5 & 92 \\
\hline & Grain 6 & 30.5 & 10.2 & 78 \\
\hline & Grain 7 & 30.5 & 11.0 & 73 \\
\hline \multirow{8}{*}{ Recrystallized } & Total & 32.8 & 9.2 & 352 \\
\hline & Grain 1 & 34.5 & 8.7 & 50 \\
\hline & Grain 2 & 34.6 & 9.0 & 50 \\
\hline & Grain 3 & 32.1 & 10.5 & 50 \\
\hline & Grain 4 & 31.1 & 7.1 & 50 \\
\hline & Grain 5 & 30.7 & 8.2 & 51 \\
\hline & Grain 6 & 34.7 & 9.2 & 50 \\
\hline & Grain 7 & 31.9 & 10.8 & 51 \\
\hline
\end{tabular}


Table II: Summary of results of cross-sectional TEM analysis of helium bubbles or cavities below surface for all microstructure and fluence conditions.

\begin{tabular}{|c|c|c|c|c|c|c|c|c|}
\hline \multirow[t]{2}{*}{ Sample } & \multicolumn{3}{|c|}{$\begin{array}{l}\text { Average size of Helium Cavities of } \\
\text { intra-grains below surface }(\mathrm{nm})\end{array}$} & \multicolumn{3}{|c|}{$\begin{array}{l}\text { Average size of Helium Cavities } \\
\text { on GBs below surface (nm) }\end{array}$} & \multirow{2}{*}{$\begin{array}{l}\text { Deepest observed } \\
\text { penetration depth, } \\
\text { grain interiors } \\
(\mathrm{nm})\end{array}$} & \multirow{2}{*}{$\begin{array}{l}\text { Deepest observed } \\
\text { penetration depth, } \\
\text { grain boundaries } \\
(\mathrm{nm})\end{array}$} \\
\hline & $0-50 \mathrm{~nm}$ & $\begin{array}{l}50-100 \\
\mathrm{~nm}\end{array}$ & $>100 \mathrm{~nm}$ & $0-50 \mathrm{~nm}$ & $\begin{array}{l}50-100 \\
\mathrm{~nm}\end{array}$ & $>100 \mathrm{~nm}$ & & \\
\hline $\begin{array}{l}\text { RX- } \\
2 \times 10^{23}\end{array}$ & $5.9 \pm 4.2$ & $4.5 \pm 1.1$ & $3.5 \pm 0.7$ & $13.4 \pm 2.4$ & $8.8 \pm 1.0$ & $3.9 \pm 0.6$ & $153 \pm 25$ & 770 \\
\hline $\begin{array}{l}\text { RX- } \\
20 \times 10^{23}\end{array}$ & $9.1 \pm 7.3$ & $6.6 \pm 4.6$ & $4.8 \pm 2.6$ & $12.4 \pm 3.8$ & $4.9 \pm 0.8$ & $3.3 \pm 0.7$ & $334 \pm 32$ & 920 \\
\hline $\begin{array}{l}\text { HR- } \\
2 \times 10^{23}\end{array}$ & $5.0 \pm 3.0$ & $2.7 \pm 0.6$ & $2.2 \pm 0.6$ & $8.0 \pm 0.4$ & $5.1 \pm 0.5$ & $3.0 \pm 0.4$ & $116 \pm 12$ & 65 \\
\hline $\begin{array}{l}\text { HR- } \\
20 \times 10^{23}\end{array}$ & $10.3 \pm 6.8$ & $5.4 \pm 1.8$ & $4.1 \pm 1.4$ & $9.0 \pm 5.5$ & $4.2 \pm 0.5$ & $3.1 \pm 0.5$ & $256 \pm 30$ & 370 \\
\hline
\end{tabular}

Note: RX, Recrystallized; HR, Hot Rolled; GB, grain boundary.

Table III: $p$-values of RX vs HR bubble distributions.

\begin{tabular}{cccc}
$\begin{array}{ccc}\text { Fluence } \\
\left(\mathrm{He} / \mathrm{m}^{2}\right)\end{array}$ & $0-50 \mathrm{~nm}$ & $50-100 \mathrm{~nm}$ & $100+\mathrm{nm}$ \\
\hline $2 \times 10^{23}$ & 0.46 & $1.0 \times 10^{-43}$ & $8.3 \times 10^{-7}$ \\
$20 \times 10^{23}$ & 0.024 & 0.019 & 0.029
\end{tabular}




\section{Hot rolled}
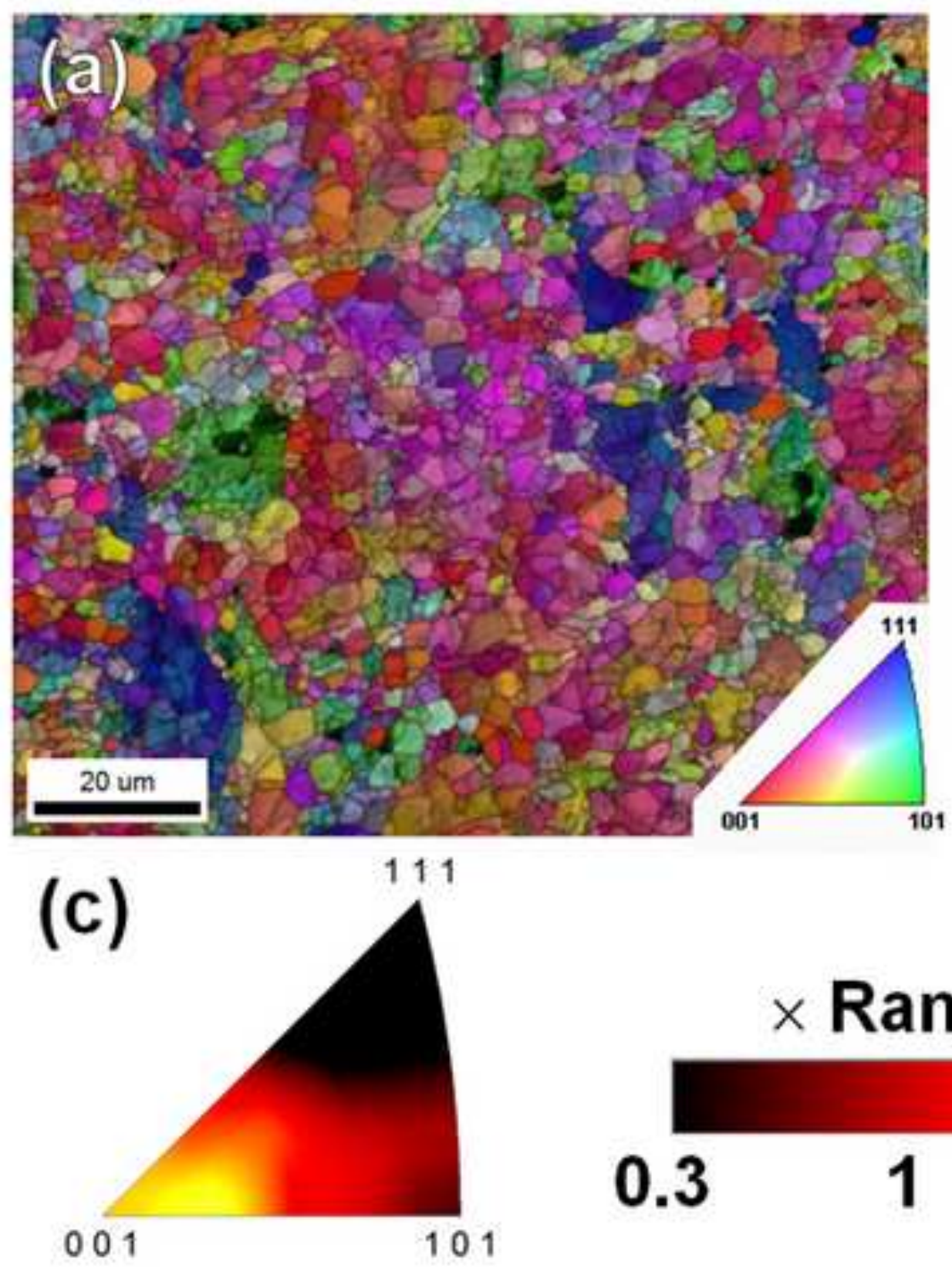

0.3

1
Recrystallized

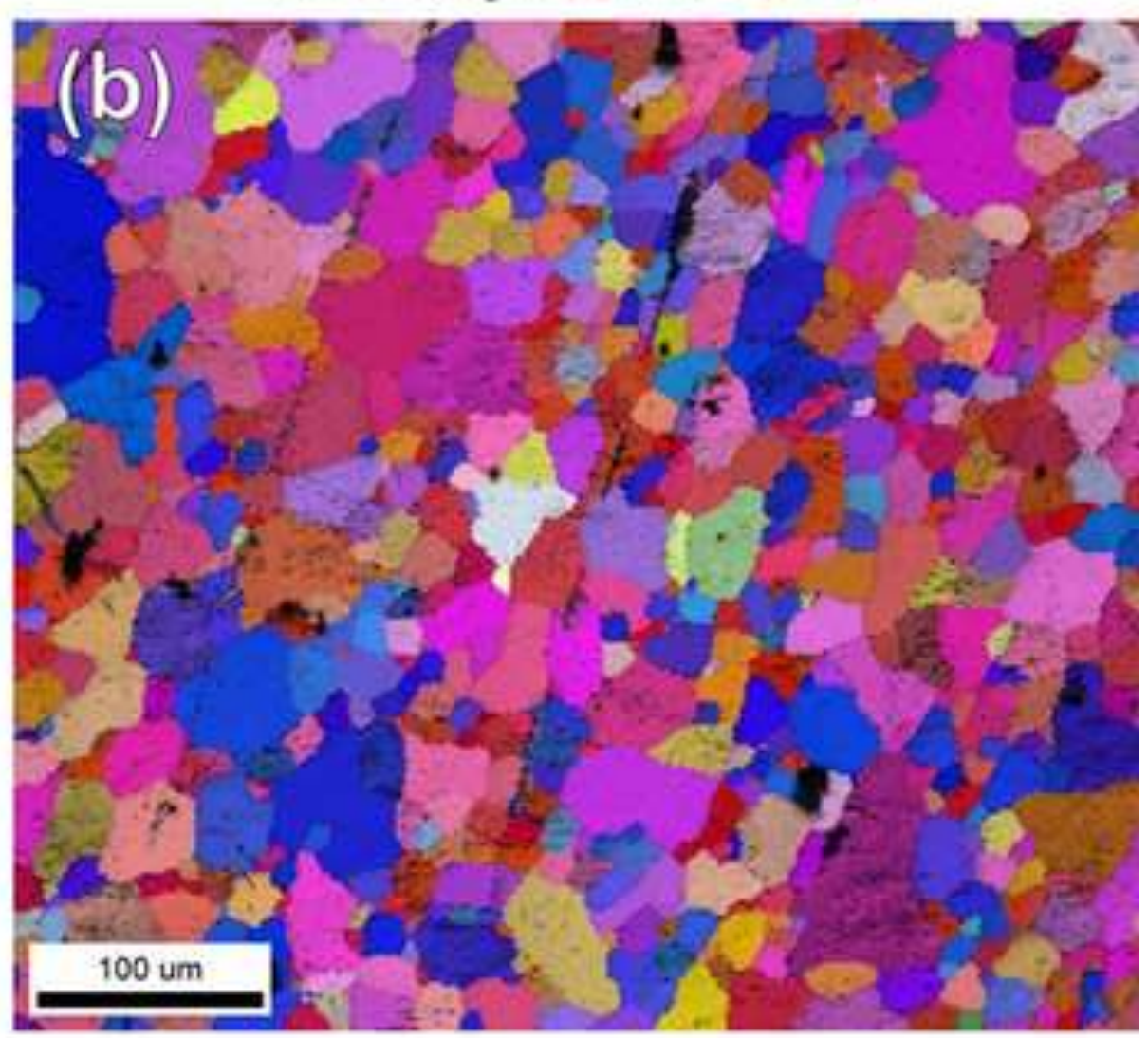

(d)

111

$\times$ Random:

5

001 


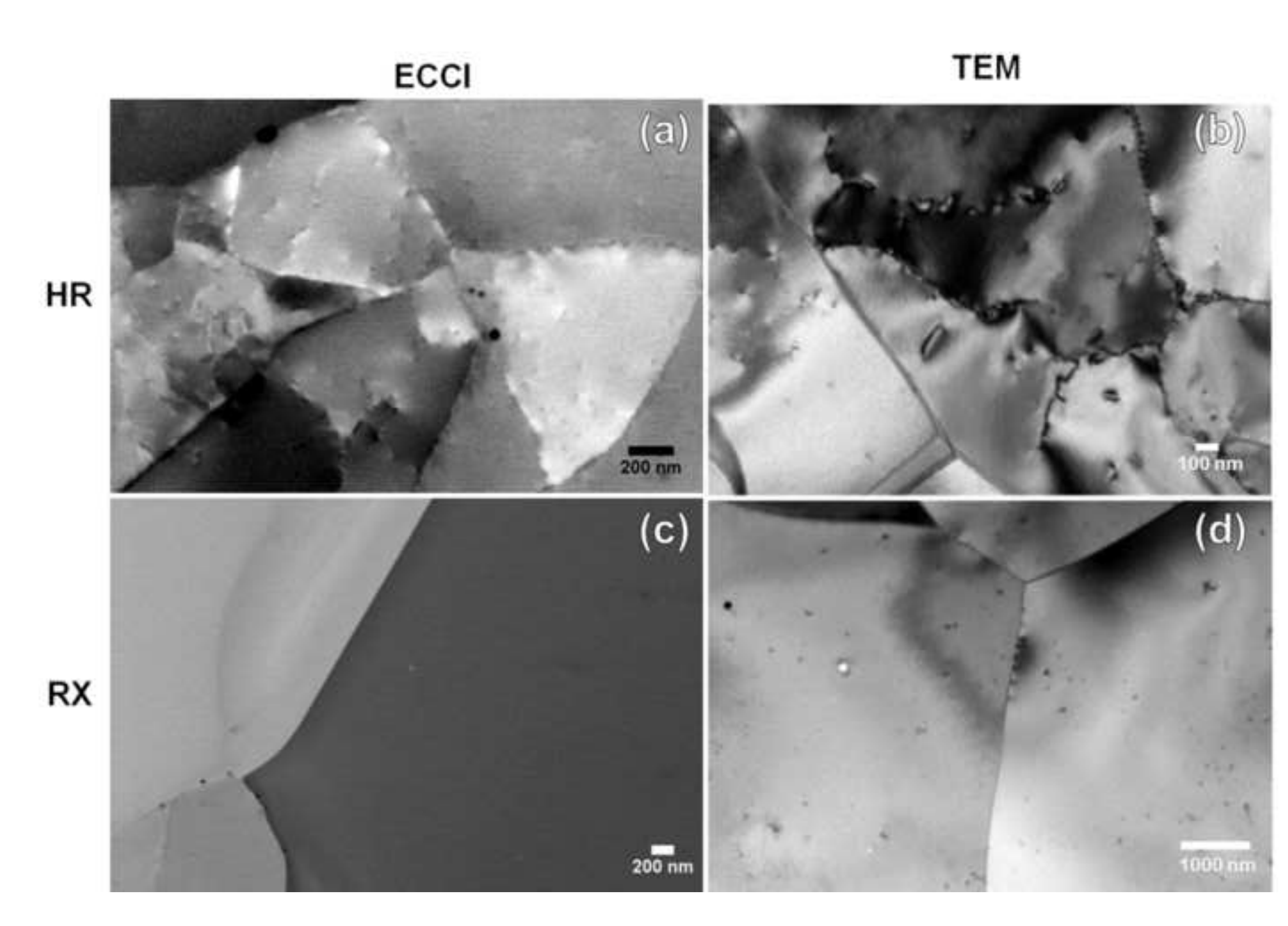

\section{Fig}
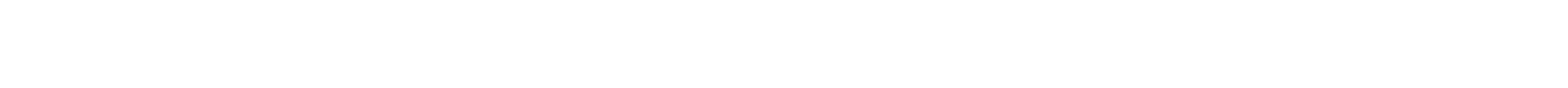
Hot Rolled

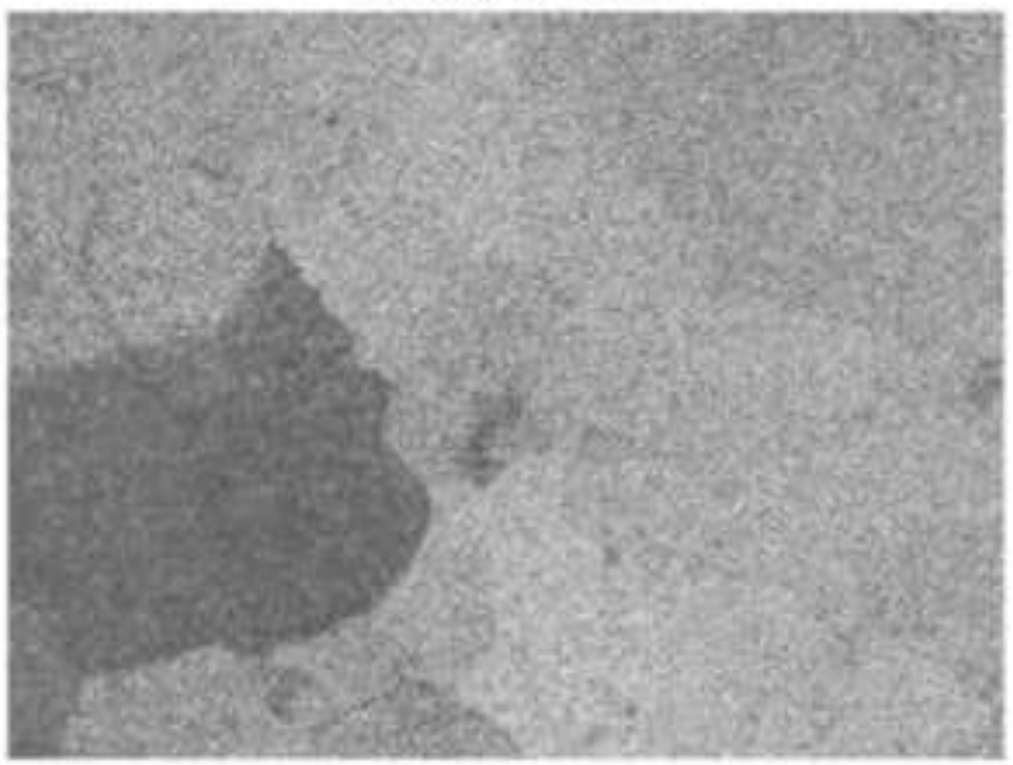

$1 \mu \mathrm{m}$

$2 \times 10^{23} \mathrm{He} / \mathrm{m}^{2}$

$2 \times 10^{24} \mathrm{He} / \mathrm{m}^{2}$
Recrystallized
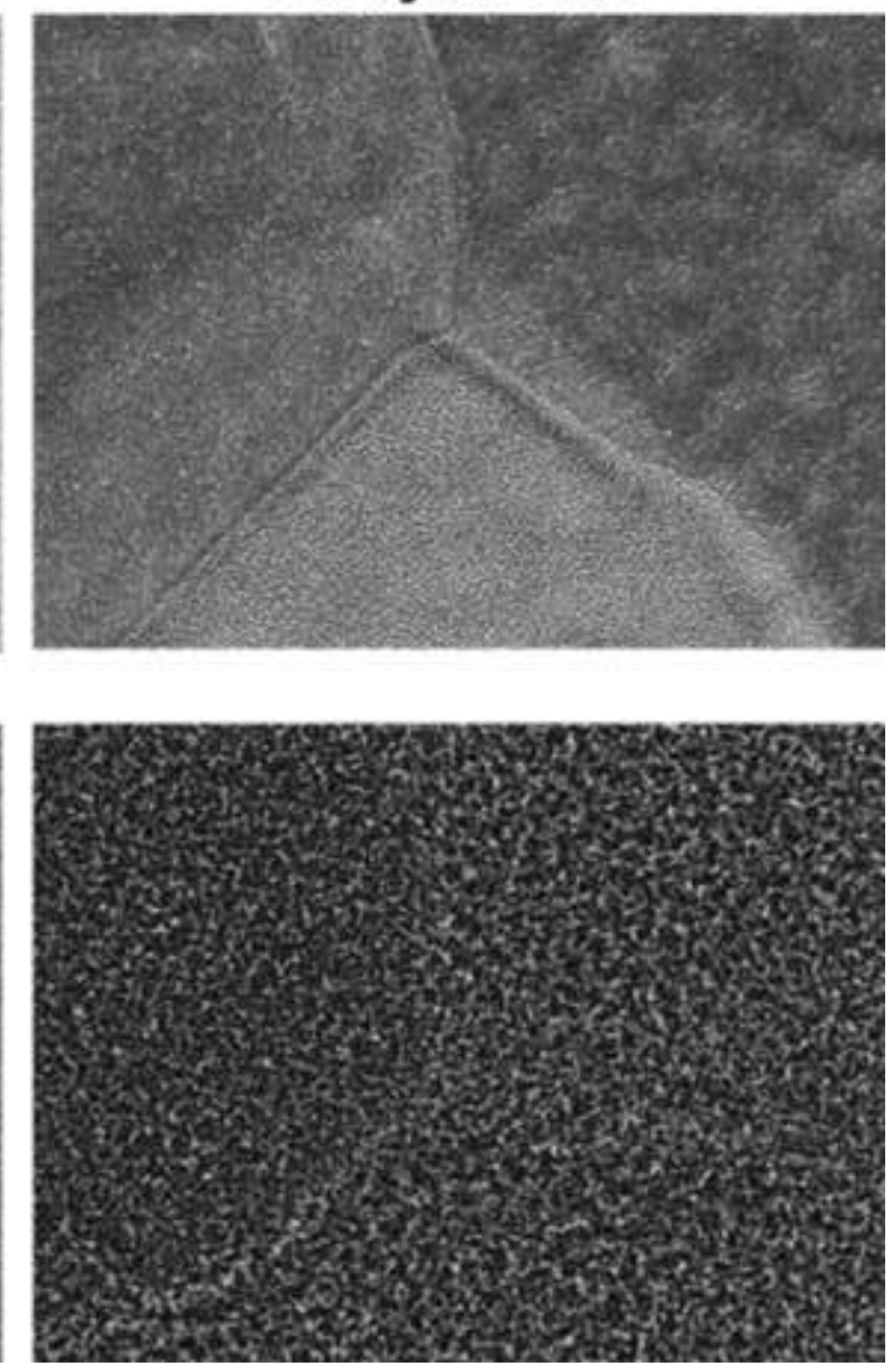

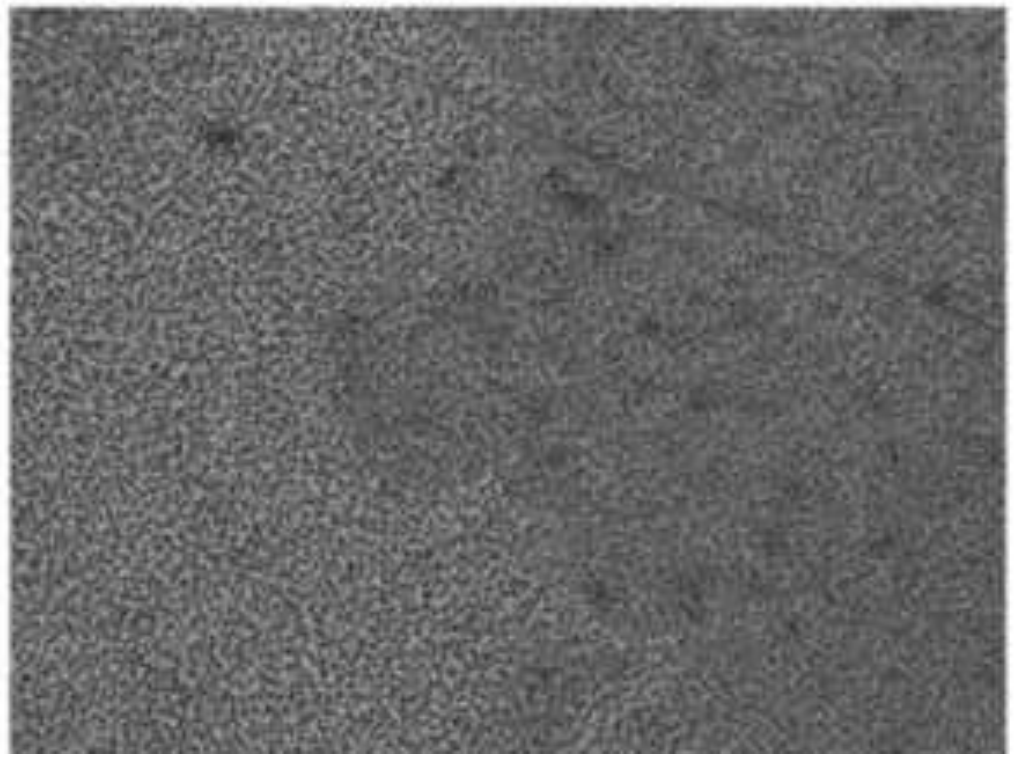


Hot Rolled

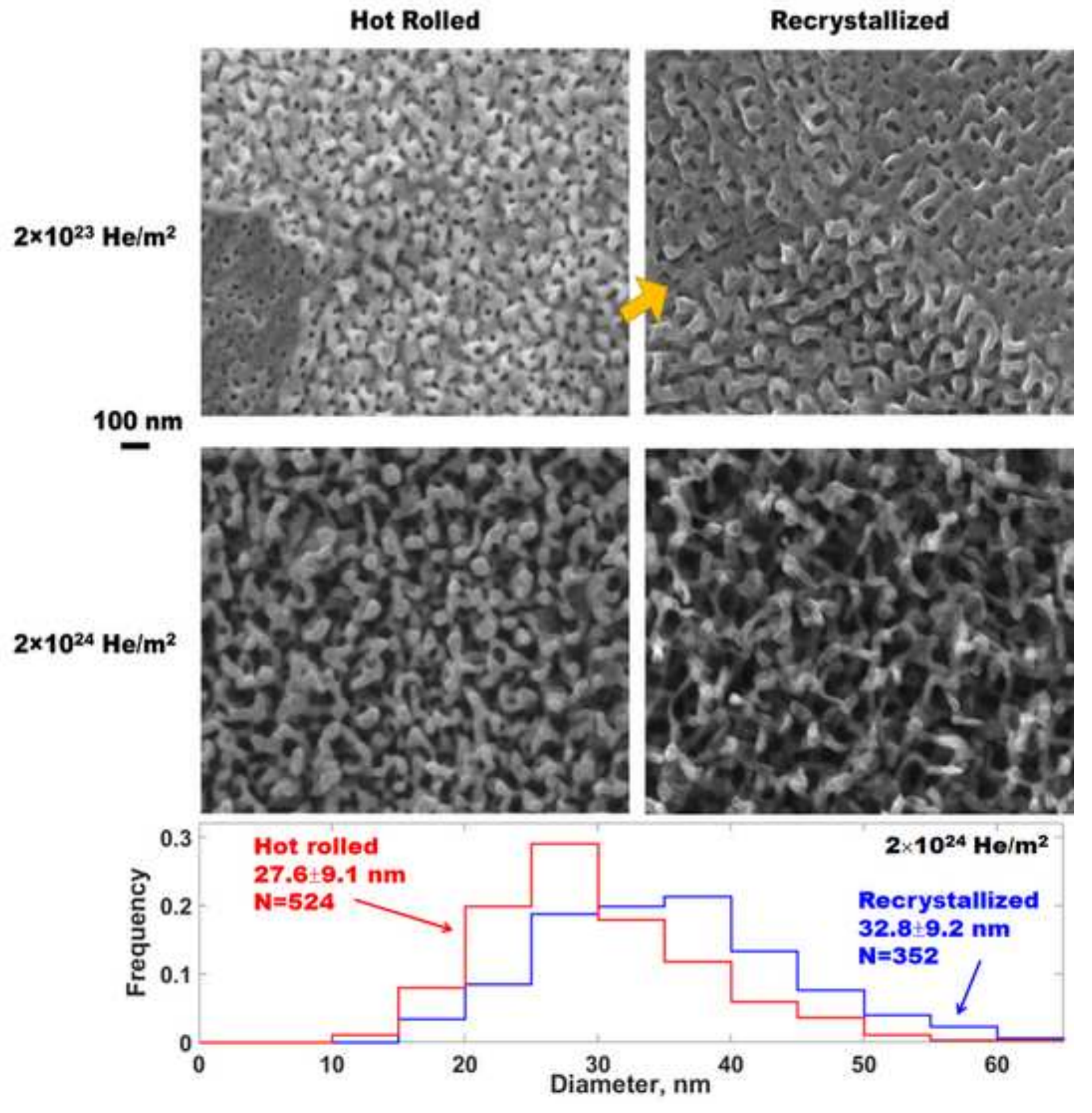

\section{Recrystallized}


Hot Rolled

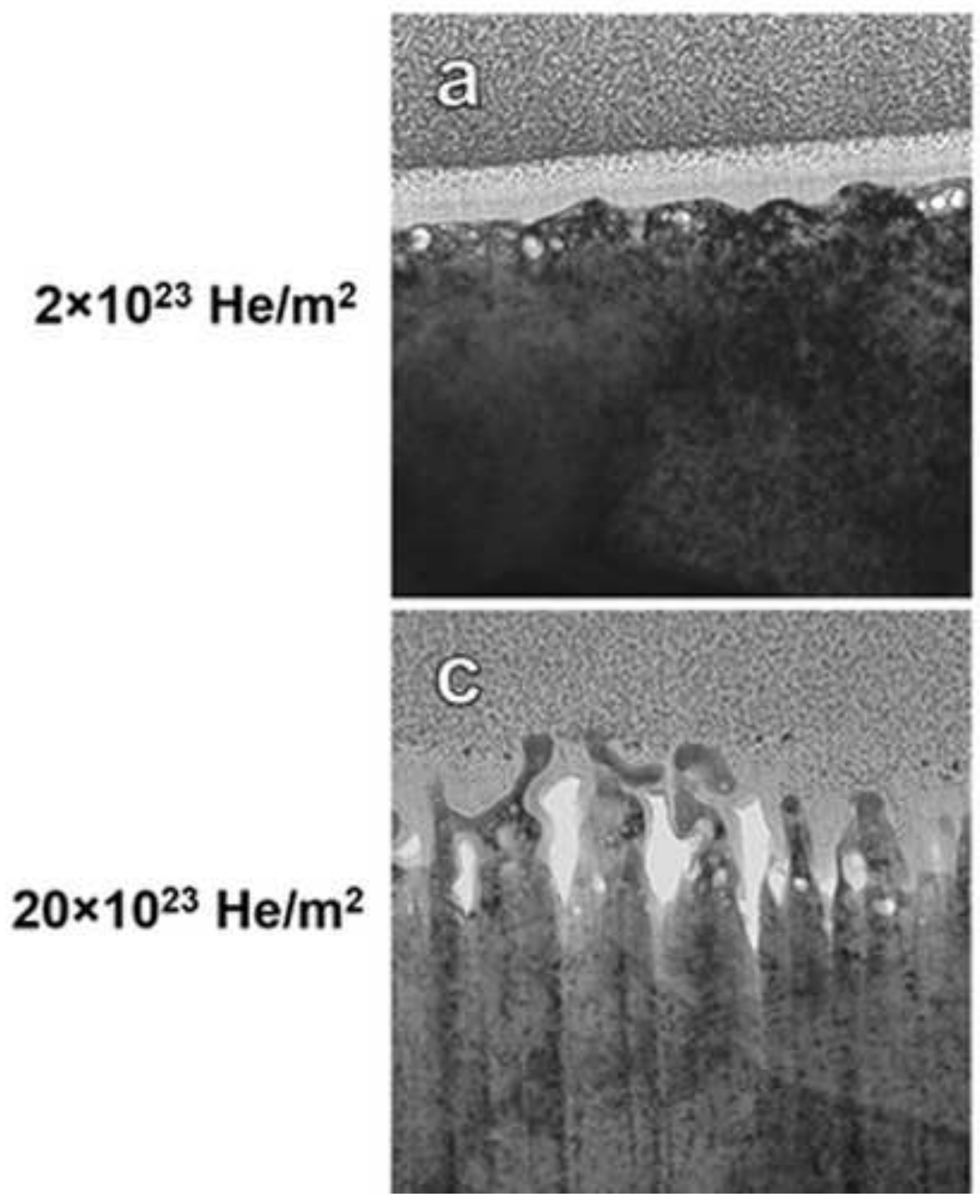

Recrystallized
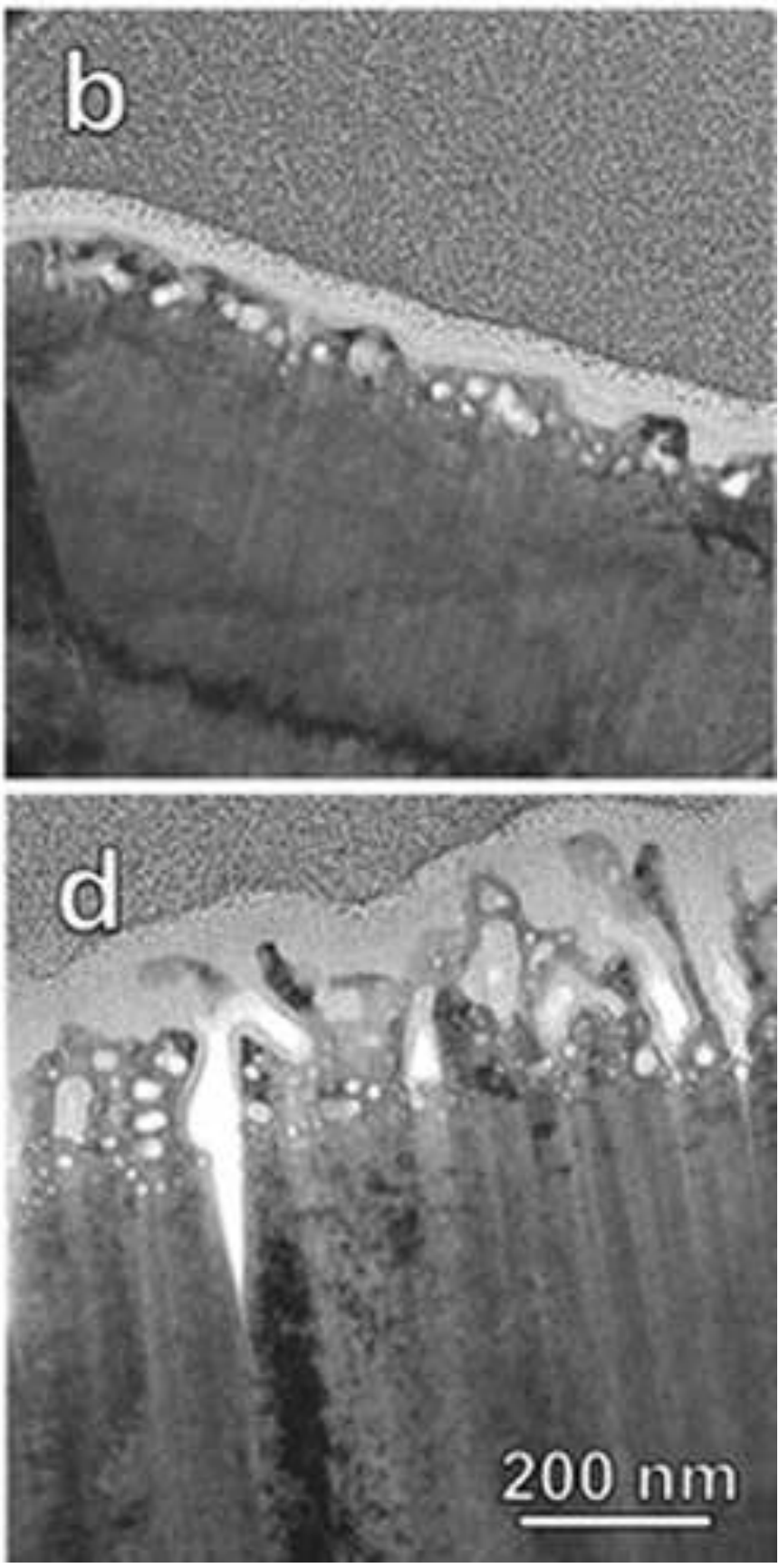
Hot Rolled

$2 \times 10^{23} \mathrm{He} / \mathrm{m}^{2}$

$20 \times 10^{23} \mathrm{He} / \mathrm{m}^{2}$

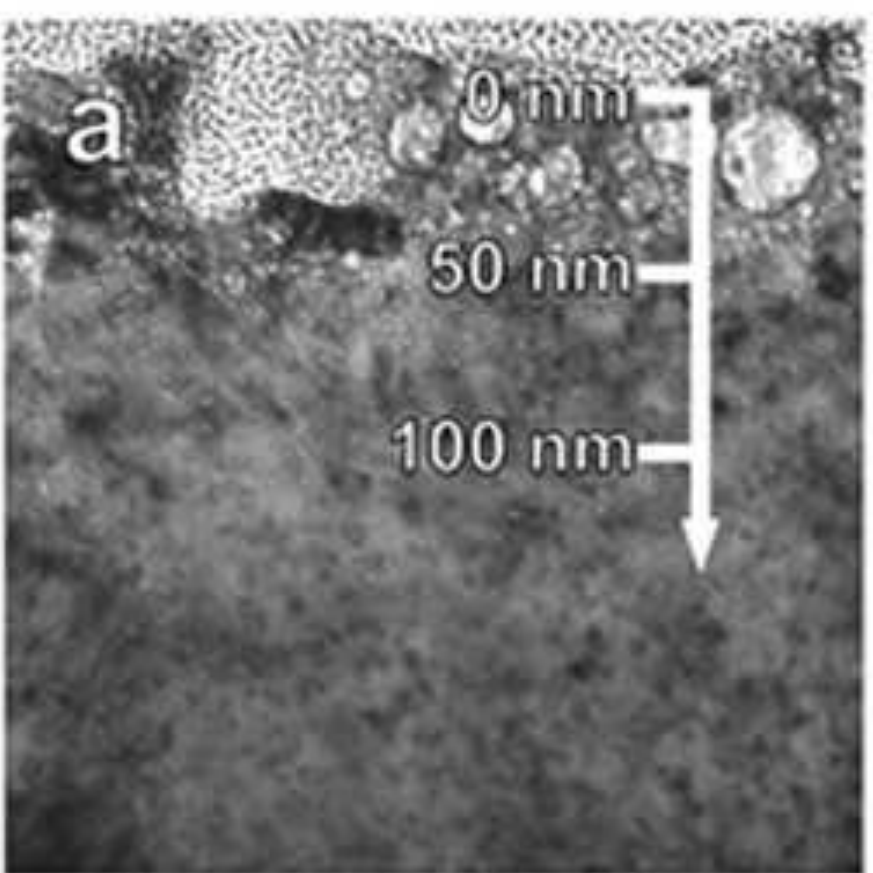

Recrystallized
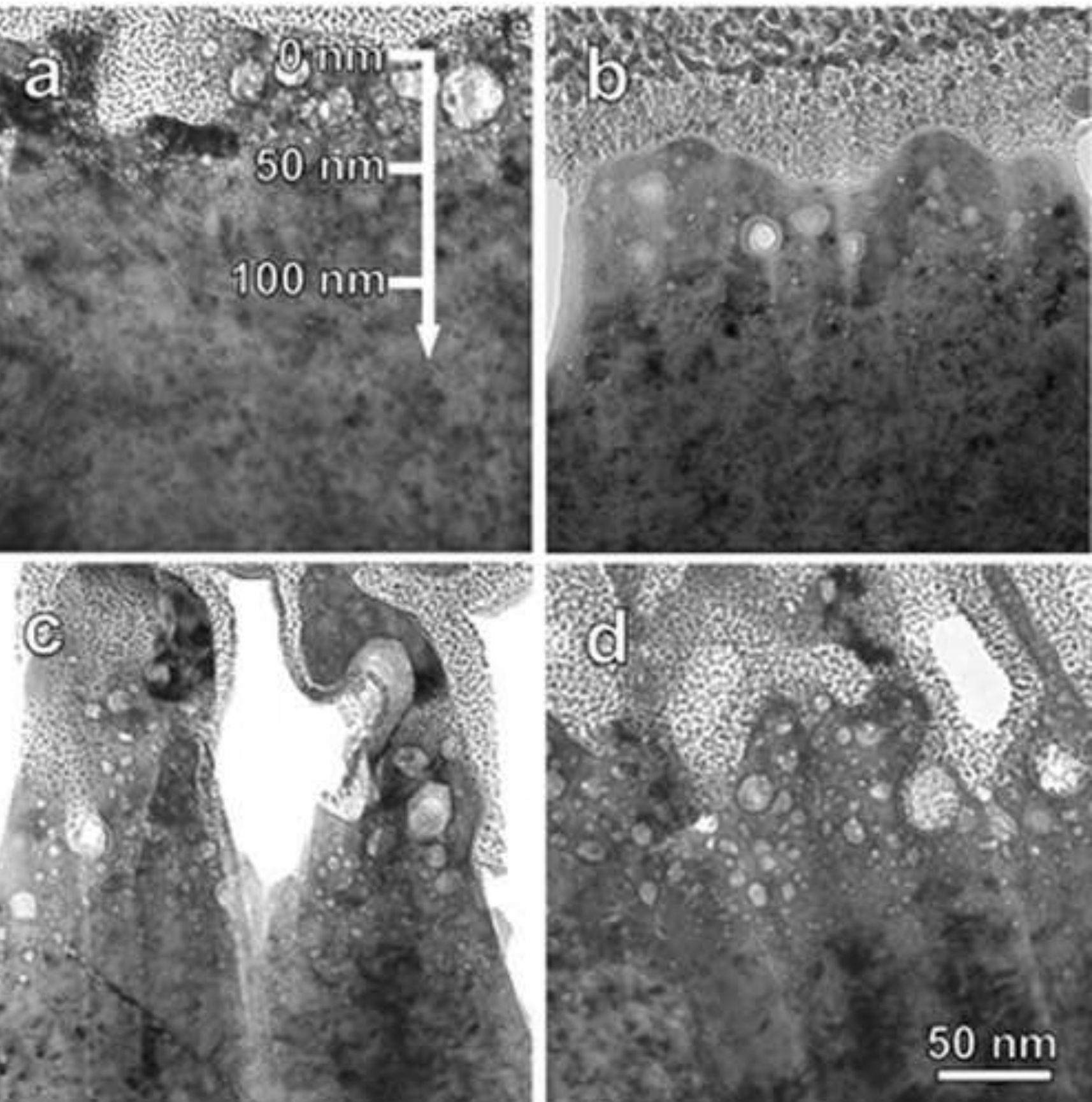

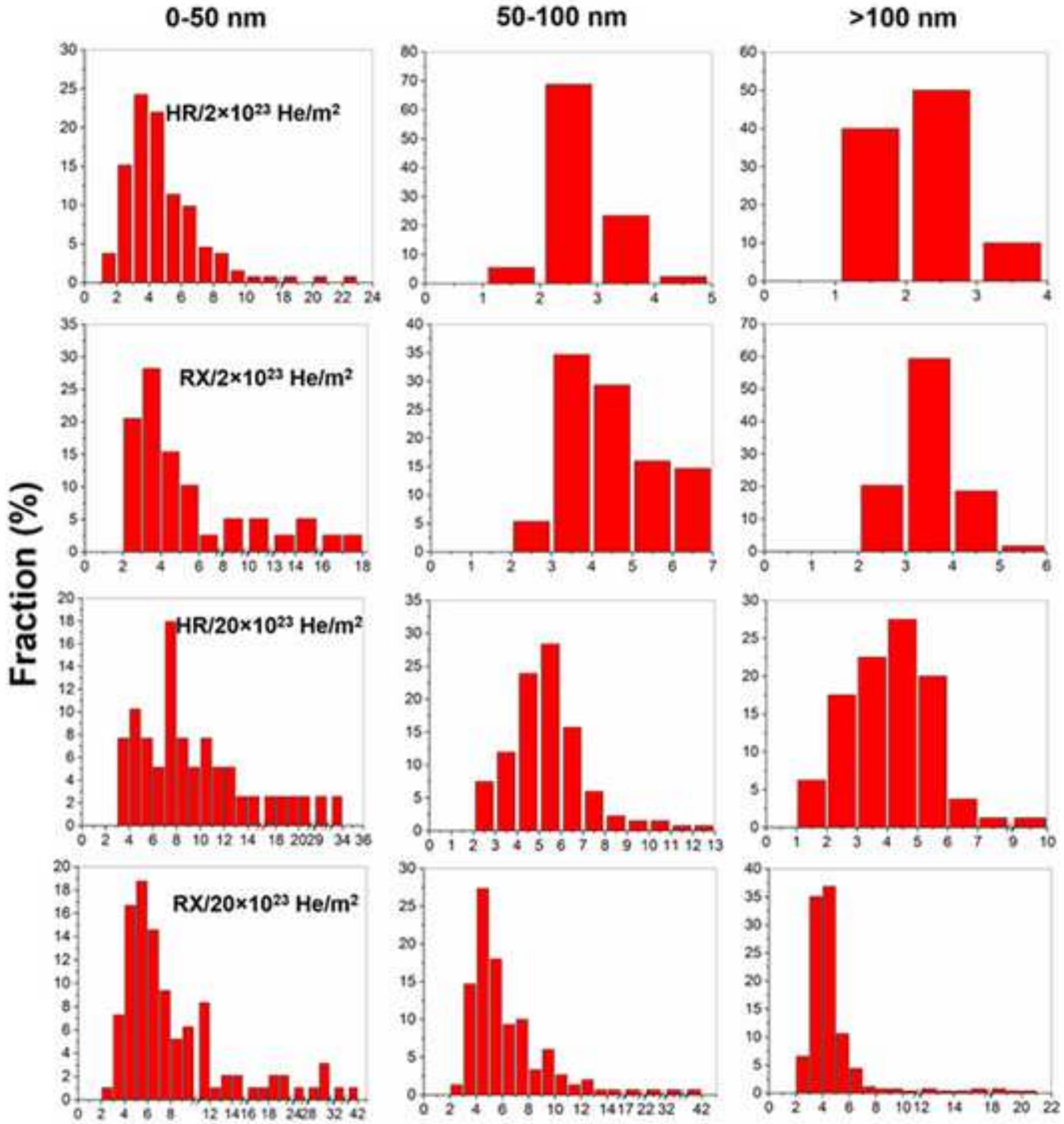

Size $(\mathrm{nm})$ 


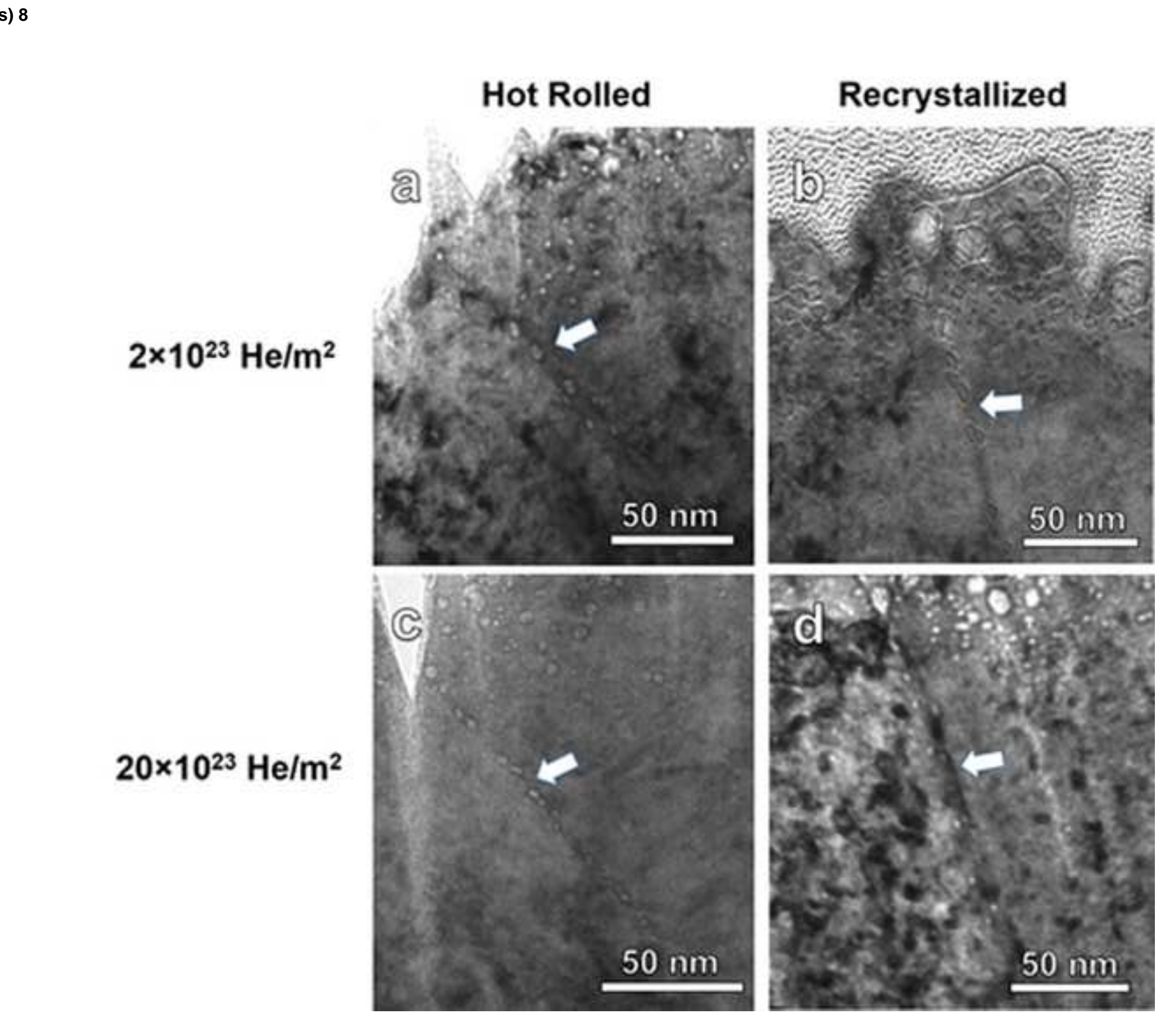

ot $\mathrm{R}$

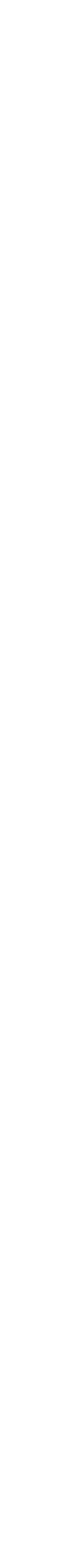

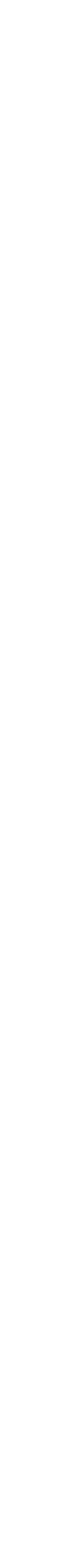

.

Fis 

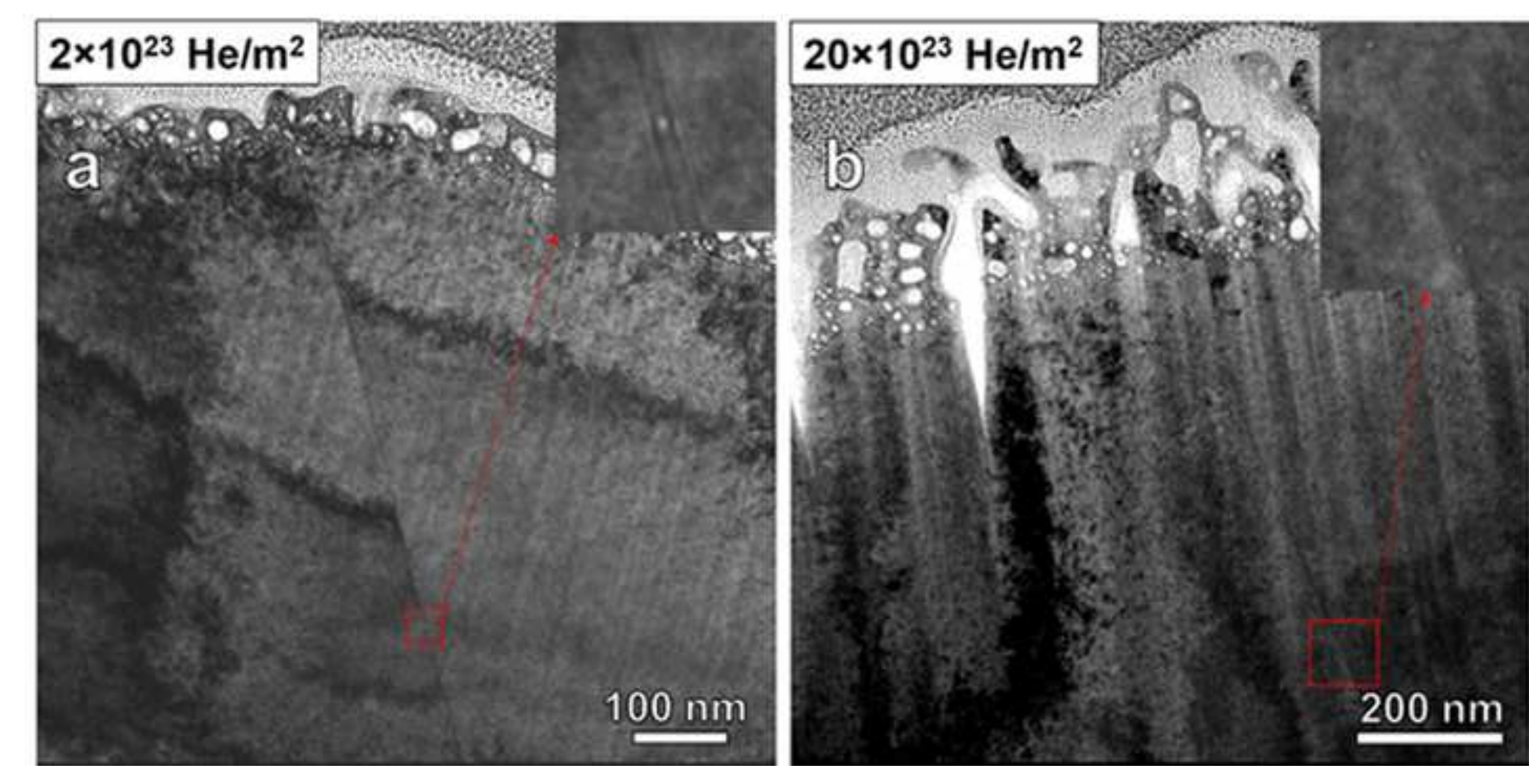


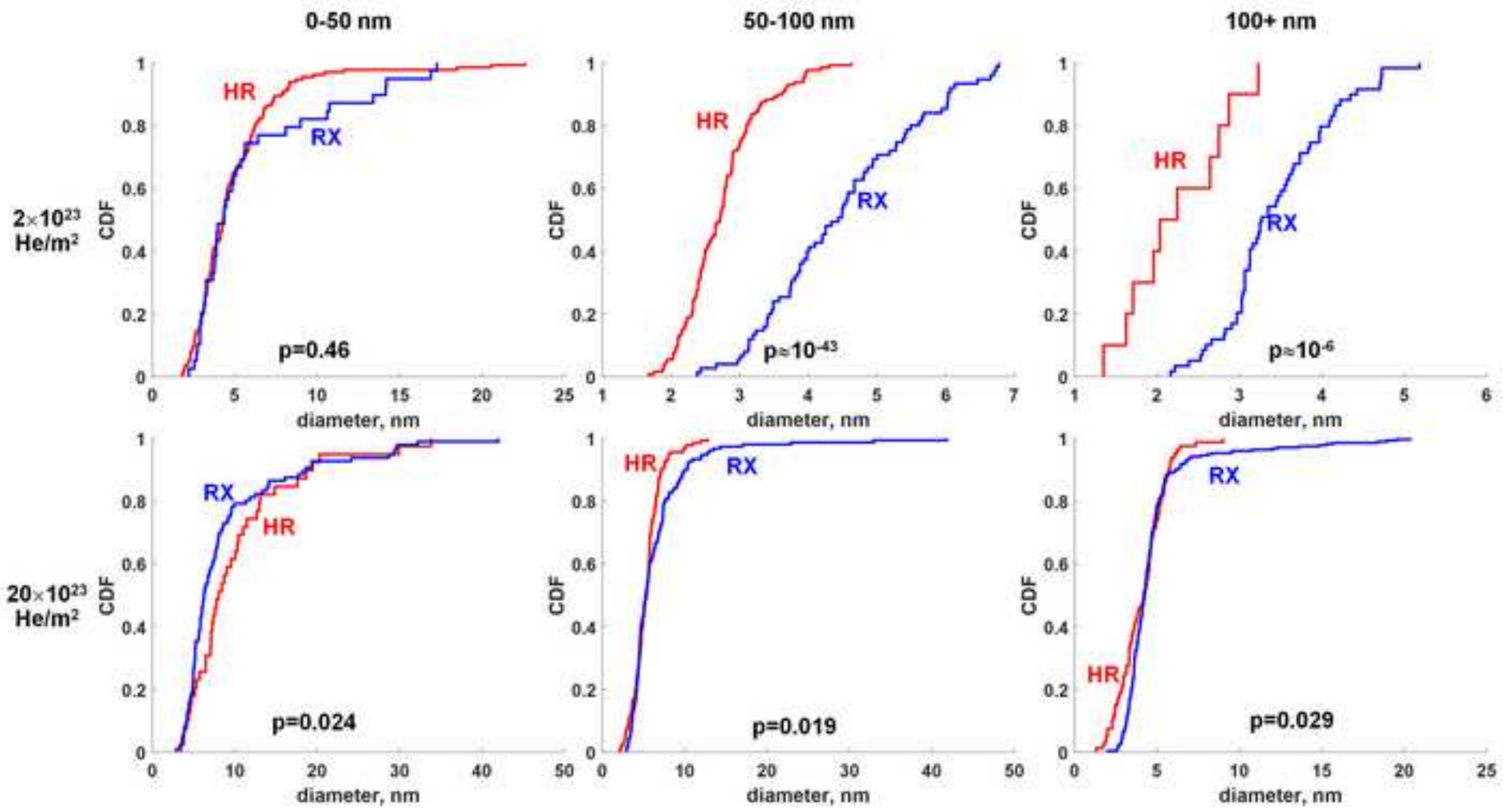




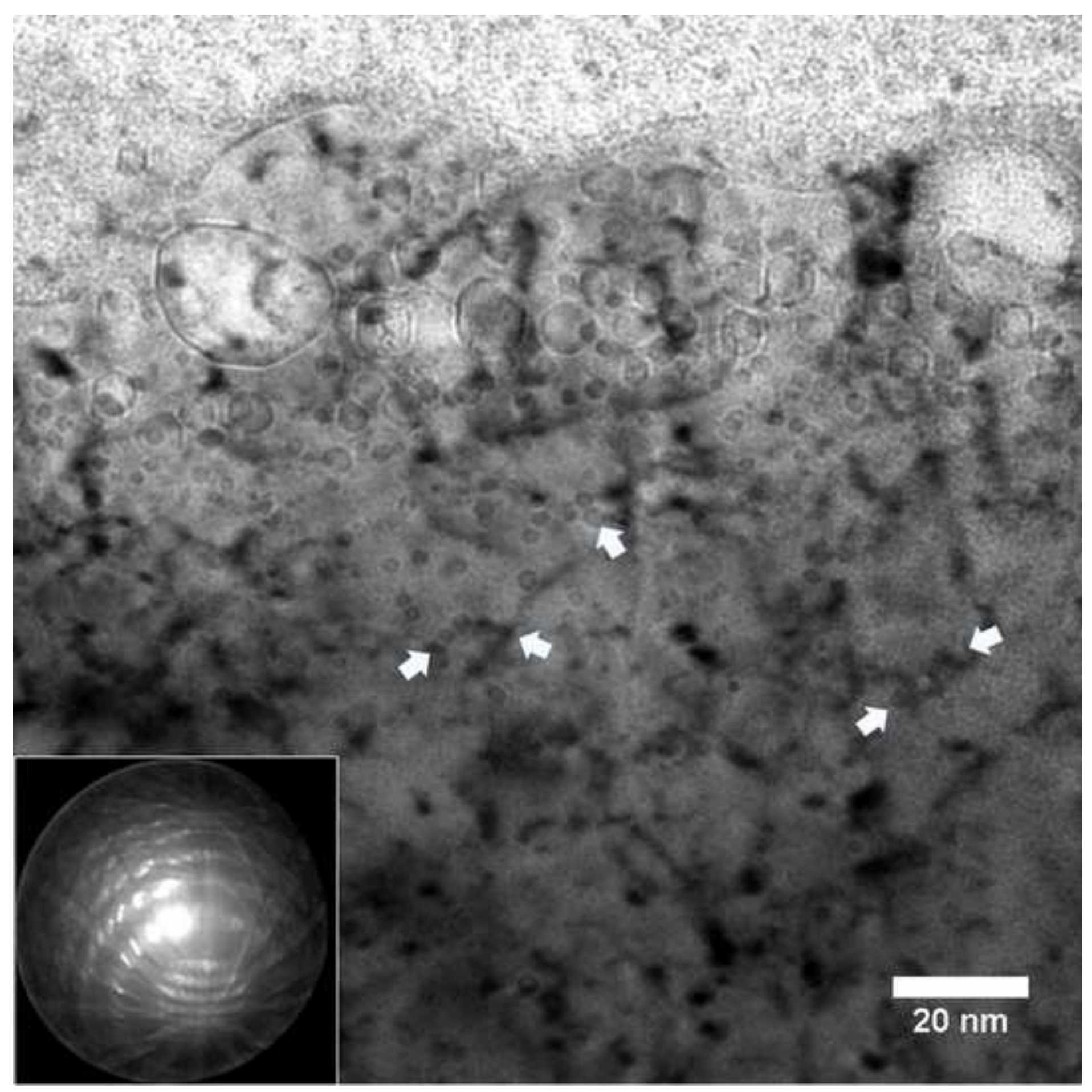

Figure(s) 11

\title{
Figure(s) 11
}
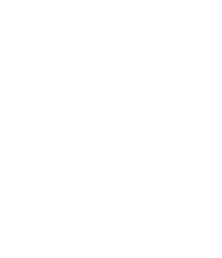

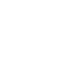

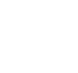

\begin{abstract}
-
\end{abstract}

\begin{abstract}
-
\end{abstract}

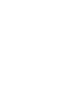

\begin{abstract}
-
-
\end{abstract}

-

\begin{abstract}
-
-
\end{abstract}

\begin{abstract}
-
\end{abstract}

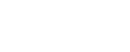


Hypothesis 1:

grain boundary diffusion
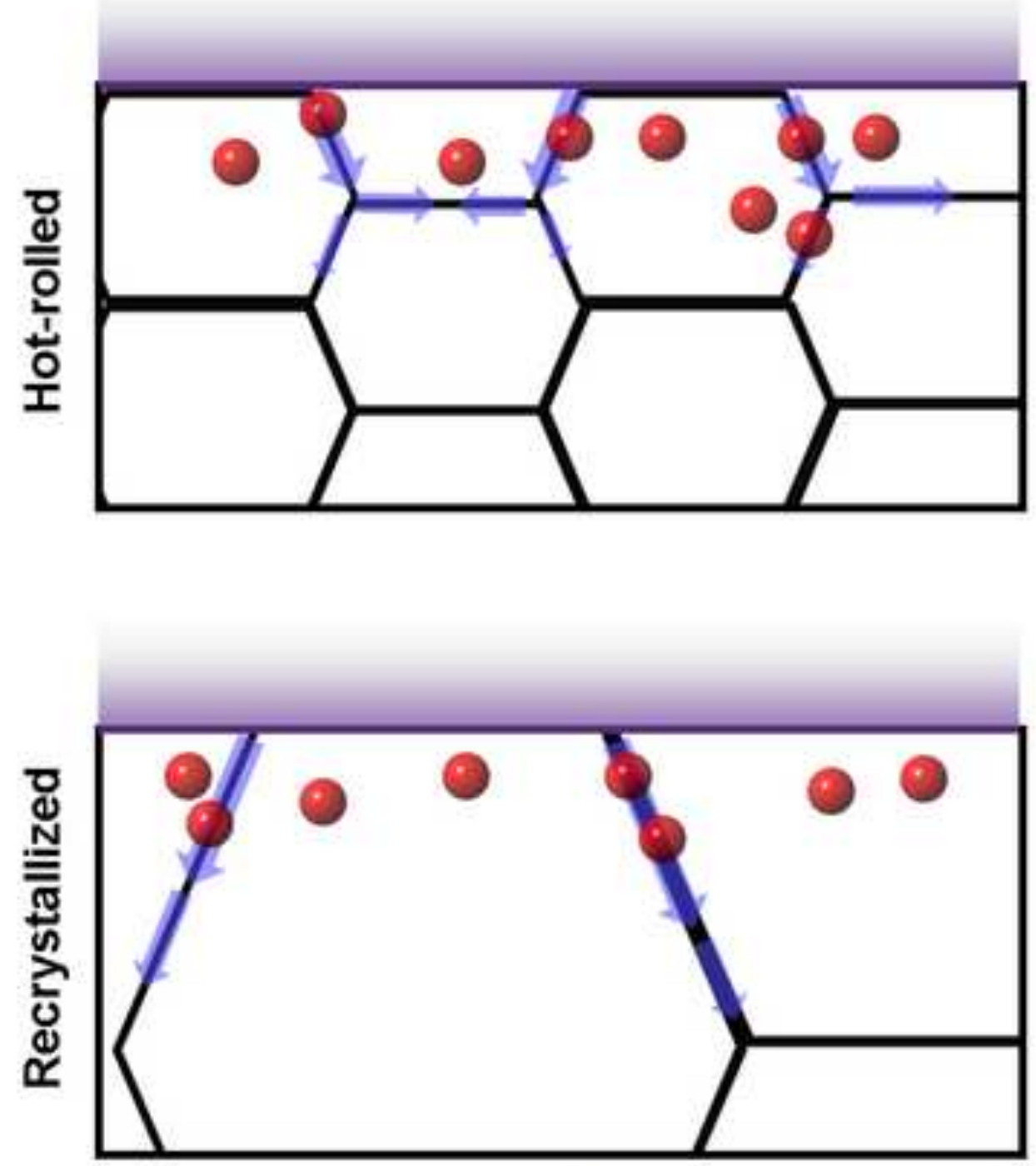

Diffusion path
Hypothesis 2: grain boundary trapping
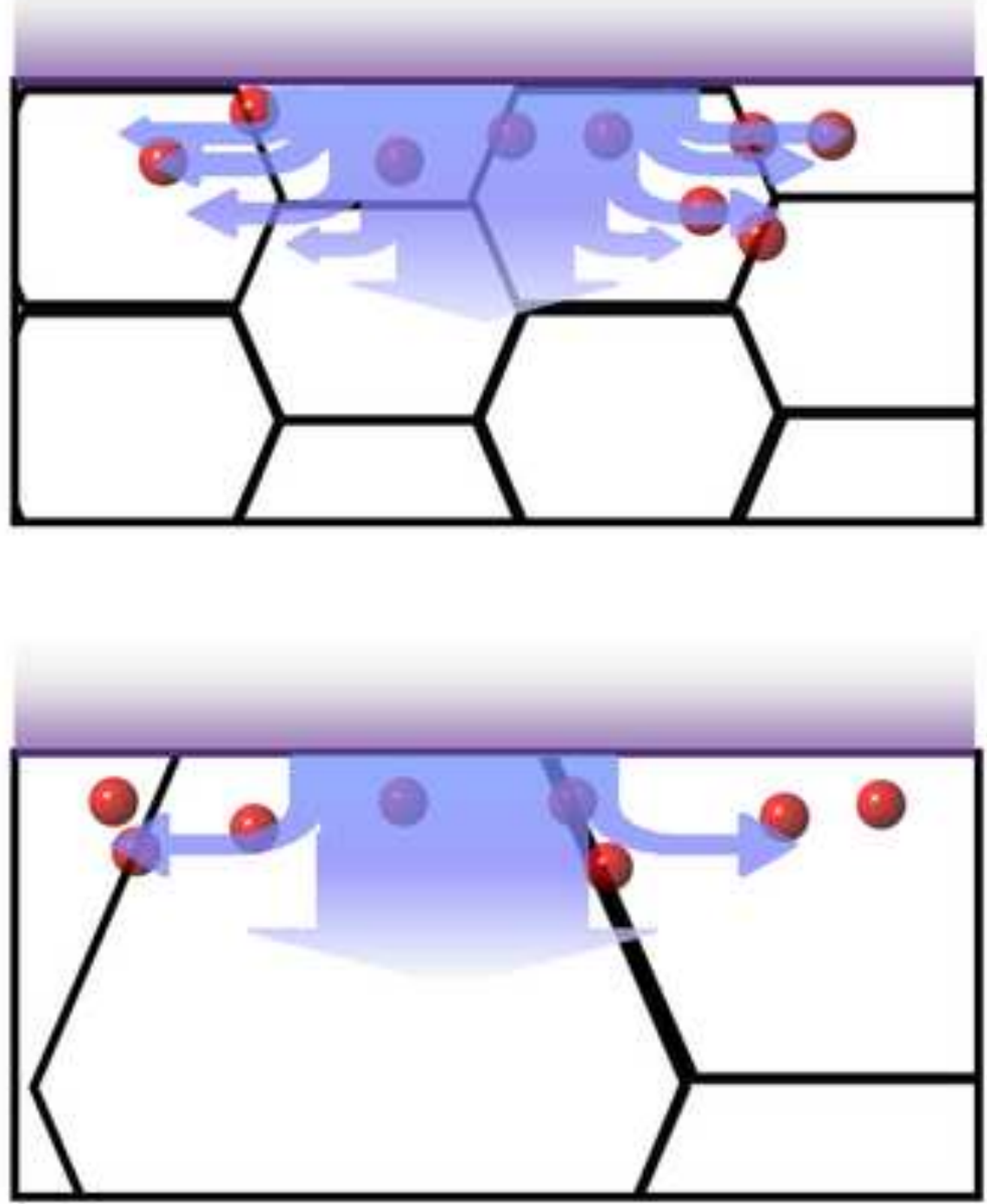

Plasma/ions 


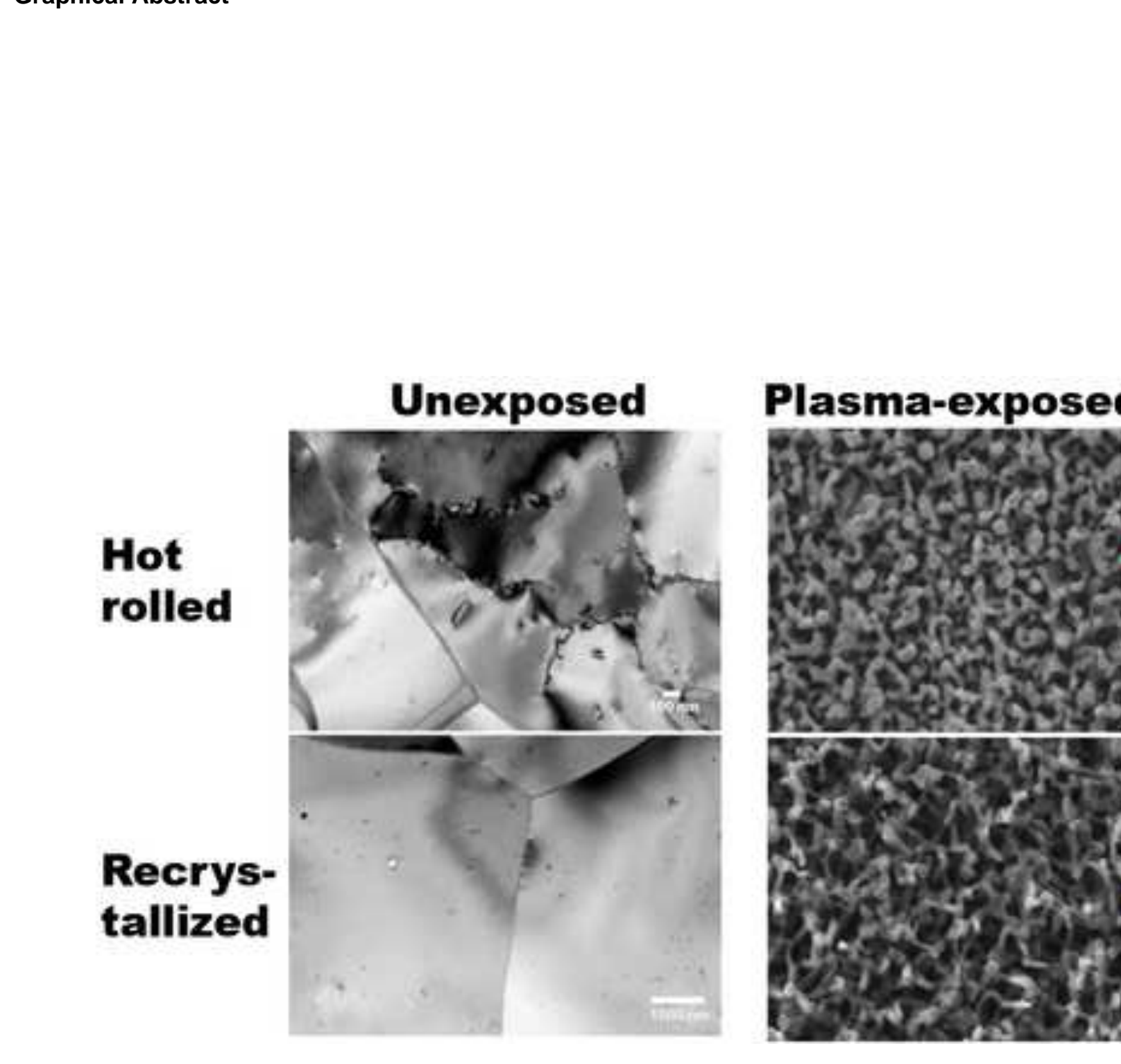

\section{Plasma-exposed}
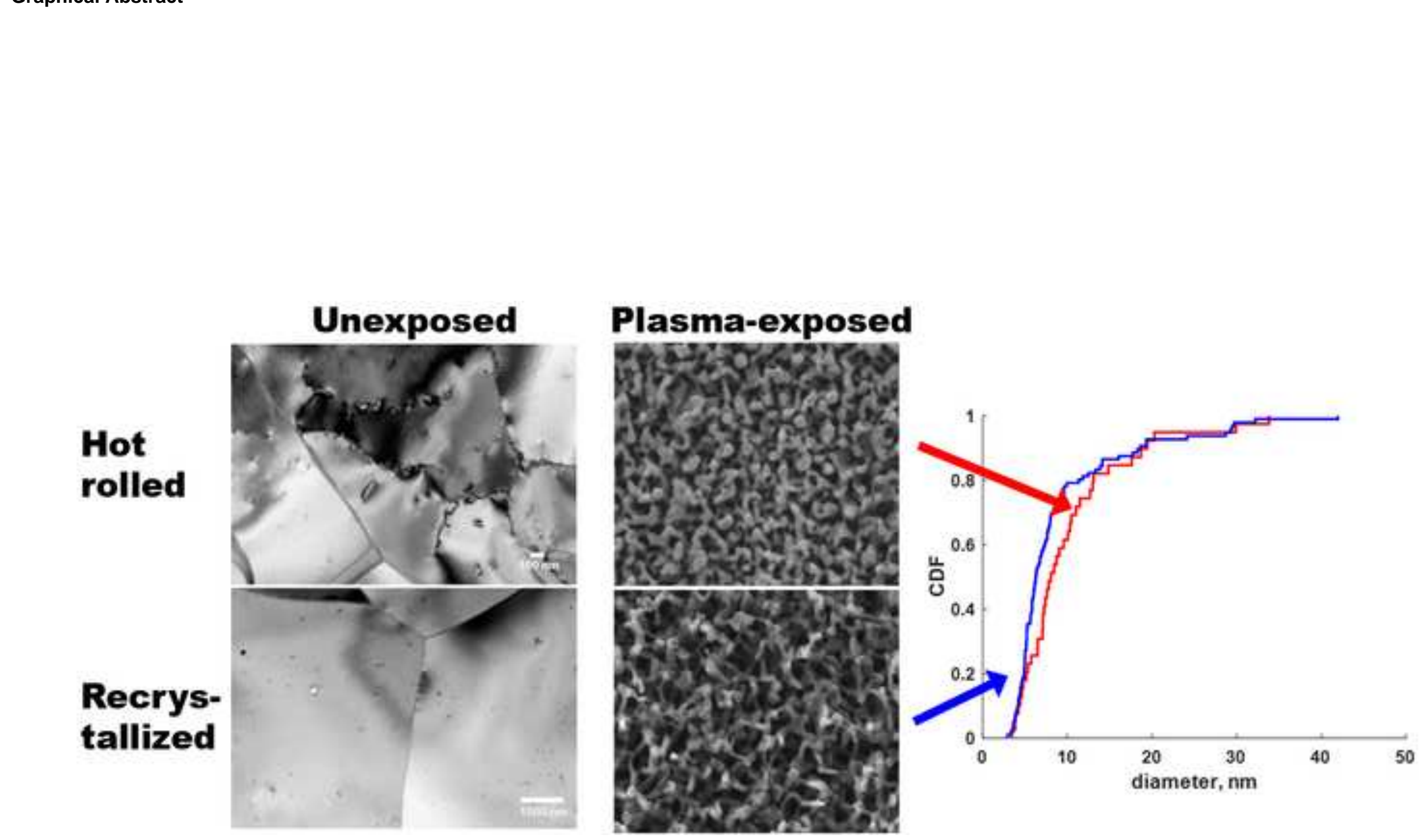